\title{
La doctrina general de los trascendentales en Dietrich von Freiberg, y su filiación aristotélico-averroísta
}

\author{
Fernanda Ocampo ${ }^{1}$
}

Recibido: 30/01/2019/ Aceptado: 06/06/2019

Resumen. El texto aristotélico Metafísica IV, 2, y sus interpretaciones por parte de los filósofos musulmanes, Avicena y Averroes, constituyen el marco teórico en el que se han elaborado las doctrinas acerca de los trascendentales, de varios autores latinos de la segunda mitad del siglo XIII de la Universidad de París, que se han posicionado en torno a la cuestión de la 'distinción real' entre el esse y la essentia. Según esto, nuestro trabajo busca trazar la dependencia de la doctrina general de los trascendentales de Dietrich, respecto de las tesis establecidas por Aristóteles en dicho texto, y en particular, respecto de la lectura averroísta - crítica de la de Avicena -, que "ha hecho escuela" en el medio parisino, especialmente entre los maestros y estudiantes de la Facultad de Artes, pero incluso también primero en Tomás de Aquino. Así, a la luz de este entramado de lecturas e interpretaciones, buscaremos delimitar los rasgos centrales de la concepción teodoriciana de los communia, señalando las posibles discrepancias o coincidencias respecto de las doctrinas de estos autores precedentes.

Palabras clave: Averroes; averroísmo latino; Avicena; Dietrich von Freiberg; 'distinción real'; Metafísica IV, 2; Tomás de Aquino; trascendentales.

\section{[en] The general doctrine of the transcendentals in Dietrich von Freiberg, and its Aristotelian-Averroist affiliation}

\begin{abstract}
The Aristotelian text Metaphysics IV, 2, and the interpretations carried out by the Muslim philosophers, i.e., Avicenna and Averroes, constitute the theoretical framework in which several Latin authors of the second half of the 13th century from the University of Paris, who have taken a stance around the question of the 'real distinction' between esse and essentia, elaborated their doctrines about transcendentals. According to this, our work seeks to trace the dependence of Dietrich's general doctrine of the transcendentals, with respect to the theses established by Aristotle in the mentioned text, and in particular, with regard to the Averroist reading - critical of that of Avicenna's -, which "has made school" in the Parisian environment, especially among the teachers and students of the Faculty of Arts, but also, first, in Thomas Aquinas. Thus, in light of this scenario of readings and interpretations, we will seek to delimit the central features of the Theodorian conception of the communia, pointing out the possible differences or coincidences with respect to the doctrines of these preceding authors.
\end{abstract}

Keywords: Averroes; Latin Averroism; Avicenna; Dietrich von Freiberg; 'real distinction'; Metaphysics IV, 2; Thomas Aquinas; transcendentals.

1 CONICET - UBA - UNR

fernandaocampob@hotmail.com

ORCID es: 0000-0003-3487-2088. 
Sumario: 1. Introducción. 2. Metafísica IV, 2 y la doctrina general de Dietrich acerca de los trascendentales. 3. La crítica de Averroes a Avicena, y su influencia en la conformación de la doctrina teodoriciana. 4. Conclusión.

Cómo citar: Ocampo, F. (2019): La doctrina general de los trascendentales en Dietrich von Freiberg, y su filiación aristotélico-averroísta, en Revista Anales del Seminario de Historia de la Filosofía 36 (3), 659-681.

\section{Introducción}

La aceptación o rechazo de la "distinción real" entre el esse y la essentia (en favor de algún otro tipo de distinción, a saber, "conceptual", "intencional" o meramente "nominal") define el carácter profundo del pensamiento ontológico de un autor, y parece condicionar especialmente su concepción acerca de las nociones primeras o nociones trascendentales. En este sentido, la posición de un autor en relación con la distinctio realis, no sólo determinaría una manera particular de comprender la especificidad de cada trascendental, sino que también influiría en la fijación de la lista y la secuencia de dichas nociones primeras. Muestras de esto último parecen ser, por ejemplo, las doctrinas de dos pensadores dominicos del siglo XIII: por un lado, la de Tomás de Aquino, y por el otro, la de Dietrich von Freiberg. En efecto, en De veritate 1.1., el Aquinate agrega a la clásica lista de los communia desde la Summa de bonno de Felipe el Canciller (a saber, 'ente', 'uno', 'verdadero' y ‘bueno'), las nociones de res y aliquid. ${ }^{2}$ También en su comentario al libro IV de la Metafísica, Tomás introduce res como propiedad trascendental, explicando que mientras este término toma su ratio de la 'esencia' de la cosa (que constituye la 'quididad'), al contrario, el nombre de 'ente' toma su ratio del 'acto de ser' del ente: ${ }^{3}$ así pues, esta diferenciación ratione entre ens y res, parecería tener su fundamento en la distinción real, establecida por Tomás, entre el ser (actus essendi) y la esencia (essentia). ${ }^{4}$ Frente a esta doctrina,

2 Tomás de Aquino, De veritate, q. 1., a. 1, resp., pp. 4-6 (Tomás de Aquino, Quaestiones disputatae de veritate, en Sancti Thomae de Aquino Opera Omnia, tomus XXII, vol. I (Praefatio - qq. 1-7), Iussu Leonis XIII P. M. edita, cura et studio fratrum praedicatorum, Romae, 1970). Tal como sostiene J. Aertsen, la trascendentalidad de estas dos nociones (res y aliquid) no era generalmente reconocida en la Edad Media: "In addition to the traditional triad, two other transcendentals are introduced in De veritate 1.1: res and aliquid. Their transcendentality was not generally recognized in the Middle Ages. There seems to be no room for an expansion of the number of communissima if, as for Philip the Chancellor and Alexander of Hales one, true and good are theologically founded in the threefold divine causality (...)" (Aertsen, Jan A. Medieval Philosophy and the Transcendentals. The Case of Thomas Aquinas, Leiden-New York-Köln: Brill, 1996, p. 109).

3 Tomás de Aquino, In Met., IV, 2, p. 155: "Sciendum est enim quod hoc nomen Homo, imponitur a quidditate, sive a natura hominis; et hoc nomen Res imponitur a quidditate tantum; hoc vero nomen Ens, imponitur ab actu essendi: et hoc nomen Unum, ab ordine vel indivisione. Est enim unum ens indivisum. Idem autem est quod habet essentiam et quidditatem per illam essentiam, et quod est in se indivisum. Unde ista tria, res, ens, unum, significant omnino idem, sed secundum diversas rationes" (Tomás de Aquino, In duodecim libros Metaphysicorum Aristotelis expositio, Cura et studio M.-R. Cathala y Raimundi M. Spiazzi, Marietti, Taurini-Romae, 1964). En adelante: Tomás de Aquino, In Met.

4 "In the text in the Metaphysics commentary, as in De veritate, Aquinas bases the conceptual difference between ens and res on a real complexity in the structure of that which is. In every thing two principles are to be considered, namely, its quiddity and its being (esse). The name res is derived from the first component, the name ens from the second. Aquinas attributes this distinction to Avicenna, but, in fact, he takes issue with Avicenna's understanding of being. According to the Arab philosopher ens is a 'concomitant' of 'thing'; it signifies some- 
se posiciona la del alemán Dietrich von Freiberg, quien, justamente rechazando la distinción 'real' entre el ser (esse) y la esencia (essentia), y no admitiendo más que una distinción entre éstos a nivel de los modi significandi, ${ }^{5}$ propone una concepción de los communia en la que, como veremos, no hay lugar para el trascendental res, y en la que una nueva noción, a saber, quid, es introducida en segundo lugar.

No obstante, hay que destacar en relación con esto que el problema del ser y la esencia, y de su distinción, tal como ha sido abordado por los pensadores medievales de finales del siglo XIII, estaba condicionado por dos importantes factores: primero, por la recepción en Occidente de las versiones árabes traducidas al latín, de la $\mathrm{Me}$ tafísica de Aristóteles, (la de Avicena en el siglo XI, y la de Averroes en el siglo XII, acompañada de su gran comentario), ${ }^{6} \mathrm{y}$ a partir de esto y de manera fundamental, por la crítica averroísta a la concepción "aviceniana" de la noción aristotélica del "uno" (y en consecuencia del "ente"). ${ }^{7}$ Así pues, influenciados por la lectura averroísta del pensamiento aviceniano, muchos latinos, creyendo encontrar en la filosofía del persa la defensa de una distinción real entre el ser y la esencia, lo han criticado en función de su supuesta concepción del "ente": a saber, la de "un accidente que se sobreañade a la esencia". ${ }^{8}$ En este sentido, como ya lo habían hecho otros maestros parisinos del siglo XIII siguiendo a Averroes, Dietrich desaprobará la doctrina de la accidentalidad del ser y del ente, en favor de lo que él considera una auténtica comprensión de estas nociones, a saber: la aristotélica de cuño averroísta. Este posicionamiento

thing added to the essence in the manner of an accident. But in Thomas's view, the esse, from which the name ens is taken, is the very actuality of every essence or nature. With personal emphasis he states: 'What I call esse is the actuality of all acts and thus the perfection of all perfections'." (Aertsen, Jan A. Medieval Philosophy as Transcendental Thought: From Philip the Chancellor (ca. 1225) to Francisco Suárez, Leiden-Boston: Brill, 2012, p. 224). Por otra parte, así reza el texto del De veritate: “(...) et sic imponitur hoc nomen res, quod in hoc differt ab ente, secundum Avicennam in principio Metaphysicae, quod ens sumitur ab actu essendi, sed nomen rei exprimit quiditatem vel essentiam entis". (Tomás de Aquino, De veritate, op. cit., q. 1, a. 1, resp., p. 5).

5 Como señala I. Rosier-Catach, la noción de modus significandi es típicamente medieval, se elabora a lo largo del siglo $\mathrm{XII}^{\circ}$, y deviene el concepto clave de la gramática especulativa del siglo $\mathrm{XIII}^{\circ}$ : ésta expresa la idea de que una palabra, además de su significación propia y primera (de naturaleza "lexical"), comporta otros componentes de otro orden. Pues bien, son estos componentes los que quedan integrados en la noción de modi significandi, que subsistirá por lo menos hasta mediados del siglo XIII ${ }^{\circ}$ : ésta corresponde, por un lado, a los atributos gramaticales secundarios o accidentes de una parte del discurso (como género, número, caso, tiempo, persona, etc.), que serán llamados consignificata, y luego, "modos accidentales de significar"; y por el otro lado, se tratará de la propiedad definitoria de una parte del discurso, que será llamada significatum generale, y después, "modo esencial de significar". De esta manera, una unidad lexical completa posee tres componentes: (1) su significado lexical o significatum speciale, (2) su propiedad esencial de ser sustantivo, verbo, etc. (o significatum generale), y (3) sus propiedades gramaticales secundarias (o consignificata) (Rosier-Catach, Irène. "Res significata et modus significandi. Les enjeux linguistiques et théologiques d'une distinction médiévale", en S. Ebbesen (ed.): Sprachtheorien in Spätantike und Mittelalter, Tübingen: Gunter Narr Verlag, 1995, pp. 135-168, p. 137). Como veremos, esta doctrina de los modi significandi (que había encontrado numerosos adherentes en la Facultad de Artes de París) es conocida y aplicada por Dietrich, no en torno al caso de los trascendentales, sino en relación con la polémica acerca de la distinción real entre el esse y la essentia. Sobre el aprovechamiento que hace Dietrich de esta doctrina para la postulación de la identidad real entre el ser y la esencia, ver: Imbach, Ruedi. "Gravis iactura verae doctrinae, Prolegomena zu einer Interpretation der Schrift De ente et essentia Dietrichs von Freiberg O.P.” (1979), reimpreso en: Quodlibeta. Ausgewählte Artikeln, Fribourg: Presses universitaires, 1996, pp. 152-207.

6 König-Pralong, Catherine. Avènement de l'aristotélisme en terre chrétienne: l'essence et la matière. Entre Thomas d'Aquin et Guillaume d'Ockham, Paris: Vrin, 2005, p. 35.

7 Henri de Gand, Gilles de Rome, Godefroid de Fontaines. Etre, essence et contingence, introd. et trad. Catherine König-Pralong, Paris: Les Belles Lettres, 2006, p. 31.

8 Wippel, John F. Metaphysical themes in Thomas Aquinas II, Washington, D.C.: Catholic University of America Press, 2007 (Studies in Philosophy and the History of Philosophy, 47), p. 45. 
constituye pues un presupuesto fundamental de su doctrina de los trascendentales, y es al análisis de este aspecto de la cuestión, al que nos dedicaremos en el presente trabajo, buscando determinar la posición general de Dietrich en torno a los communia, ${ }^{9}$ y dejando para alguna otra ocasión el estudio de la especificidad de cada noción, en conexión con la temática referida al rechazo de la distinción real por parte del filósofo alemán. Así pues, analizaremos en primer lugar la recepción del texto de Metafísica IV, 2 en la obra de Dietrich, en conexión con su doctrina general de los trascendentales; luego profundizaremos en la interpretación averroísta de este texto aristotélico y en la crítica del cordobés a la lectura de Avicena, mostrando los puntos que pudieron haber influido (directamente o mediante otros autores) en la conformación de la doctrina teodoriciana; finalmente, expondremos nuestras conclusiones.

\section{Metafisica IV, 2 y la doctrina general de Dietrich acerca de los trascendentales}

En su obra De quiditatibus entium, leemos estas significativas líneas:

Y porque ente [ens], 'lo que' [quid], verdadero [verum], uno [unum] y [nociones] similares son trascendentales, no sólo recorren todos los entes, sino también se convierten según los supuestos. Aunque difieran por sus nociones propias, hay entre ellos un cierto orden. El ente, según su razón propia, es el primero de todos [los trascendentales], en segundo lugar es el 'lo que' [quid], y luego los otros, como se evidencia a partir del orden esencial dispuesto entre ellos. ${ }^{10}$

En este breve texto el dominico alemán sostiene tres grupos de tesis de gran importancia: en primer lugar, los trascendentales circulan a través de todos los entes y se convierten en cuanto a sus supuestos; en segundo lugar los trascendentales poseen, cada uno, una "noción” o "razón” (ratio) propia, y según esta razón difieren entre sí; finalmente, existe entre ellos un orden esencial, y según este orden, "ente”(ens) es

\footnotetext{
J. Aertsen ha dedicado ya un artículo a la consideración de la doctrina de los trascendentales en Dietrich von Freiberg: Aertsen, Jan A. "Die Transzendentalienlehre bei Dietrich von Freiberg", en K.-H. Kandler, B. Mojsisch, F.- B. Stammkötter (dir.): Dietrich von Freiberg. Neue Perspektiven seiner Philosophie, Theologie und Naturwissenschaft, Amsterdam - Philadelphia: Grüner, 1999, pp. 23-47. No obstante, su perspectiva allí es otra: luego de analizar los diferentes motivos que pudieron llevar a la conformación de una doctrina medieval de los trascendentales en el siglo XIII, analiza la doctrina de Dietrich en la línea de pensamiento de la llamada "Escuela dominicana alemana", mostrando la influencia que el dominico alemán ha ejercido sobre la concepción de Bertoldo de Moosburgo. Finaliza su estudio con una caracterización de las tres nociones más elaboradas por Dietrich: ens, quid, y unum (ver también: Aertsen, J. A. Medieval Philosophy as Transcendental Thought, op. cit., pp. 315-329, en donde a su vez se refiere brevemente al trascendental bonum). Nuestro trabajo, en cambio, busca trazar la dependencia de la doctrina general de los trascendentales en Dietrich, respecto de las tesis establecidas por Aristóteles en Metafísica IV, 2, y de la interpretación averroísta de este texto (que ha hecho "escuela" en el medio parisino, especialmente entre los maestros y estudiantes de la Facultad de Artes, pero incluso también primero en Tomás). Es con respecto a esto, que esperamos hacer nuestra contribución principal.

10 Dietrich von Freiberg, De quiditatibus entium, 7 (3), p.109: "Et quoniam ens et quid et verum et unum et similia sunt transcendentia, et circueunt omnia entia et secundum supposita convertuntur. Quamvis propriis rationibus differant, est tamen in eis aliquis ordo. Ens enim secundum suam propriam rationem omnium est primum, deinde quid est, deinde alia, ut patet ordine essentiali ad invicem disposita." (Dietrich von Freiberg, De quiditatibus entium, en Opera omnia (bajo la dirección de K. Flasch) Schriften zur Naturphilosophie und Metaphysik, Corpus Philosophorum Teutonicorum Medii Aevi, Tomus 3, introducción de K. Flasch, eds. J.-D. Cavigoli, R. Imbach, B. Mojsisch, M. R. Pagnoni-Sturlese, R. Rehn, L. Sturlese, Hamburg: Felix Meiner Verlag, 1983, pp. 97-118). En adelante: Dietrich von Freiberg, DQE.
} 
primero, luego "lo que" (quid), y por último las restantes nociones en función de este ordenamiento. Lo que llama la atención desde el comienzo, ya que esto constituye una verdadera novedad en la historia conocida de la configuración de las nociones trascendentales, es el hecho de que una nueva noción es introducida en segundo lugar (luego del ens), a saber: quid. ${ }^{11}$ Como lo hemos anticipado, esta opción por parte del dominico alemán no parece ser gratuita: la ausencia de la noción de res, y la presencia de quid en segundo lugar, se deben, en nuestra opinión, a elecciones en materia de ontología, bien precisas y definidas, que sobreentienden el rechazo de la "distinción real" entre esse y essentia, y que colocan a la "quididad" (que desciende de quid mediante una abstracción) en el territorio exclusivo de la forma substancial. No obstante, el "reemplazo" de una noción por la otra no incide de manera decisiva en la configuración de su doctrina "general" de los trascendentales, de modo que no ahondaremos aquí en esa interesante cuestión.

Ahora bien, que los trascendentales circulen a través de todos los entes y se conviertan en cuanto a sus supuestos, constituye una doctrina que tiene su origen en las tesis aristotélicas relativas a las nociones de "ente" y "uno". En efecto, en Metafísica IV, $2,{ }^{12}$ el Estagirita sostiene que aunque "ente" y "uno" sean nociones diferentes, son lo mismo en la realidad: así, reenviando a un mismo supuesto real, es decir, siendo numéricamente algo "uno" en cuanto al supuesto, estas nociones diferentes pueden intercambiarse en la predicación, y así decimos que son "convertibles" ${ }^{13} \mathrm{De}$ manera similar, existe otra "situación de igualdad" entre "ente" y "uno", a saber, en lo referido a su extensión, y a las categorías o especies en las que ambos se dividen: en este sentido, las dos nociones poseen amplitud universal, puesto que se dicen de cada una de las diez categorías (la substancia y los nueve accidentes). ${ }^{14}$ Pues bien, estas tesis conforman un conjunto, aceptado en su integralidad por numerosos autores de los siglos XI, XII y XIII, que, como veremos, han seguido la exposición de Aristóteles en la Metafísica: a saber, entre otros, y con un especial interés para nosotros, Avicena, Averroes, Tomás de Aquino, Sigerio de Brabante, Godofredo de Fontaines. De la misma manera, Dietrich afirma la "convertibilidad" in suppositis ${ }^{15}$ de las nociones trascendentales, así como también su extensión universal y su "circulación" a través de todos los predicamentos o categorías.

11 “Der Platz, welchen Dietrich dem 'quid' einräumt, ist auffallend, weil im 13. Jahrhundert diese Bestimmung nicht aufgelistet wird” (Aertsen, J. A. "Die Transzendentalienlehre bei Dietrich von Freiberg”, op. cit., p. 37).

12 Aristoteles latinus, Metaphysica IV, 2, pp. 68-69: "Si igitur ens et unum idem et una natura eo quod se ad inuicem consequuntur sicut principium et causa, sed non ut una ratione ostensa (nil autem differt nec si similiter suscipiamus, sed et pre opere magis). Idem enim unus homo et homo, et ens homo et homo, et non diuersum aliquid ostendit secundum dictionem repetitam 'est homo et homo et unus homo'; palam autem quia non separatur nec in generatione nec in corruptione. Similiter autem et in uno, quare palam quia additio in hiis idem ostendit, et nichil aliud unum preter ens. Amplius autem cuiusque substantia unum est non secundum accidens, similiter autem et quod quidem ens aliquid. Quare quotcumque unius sunt species, tot et entis (...)" (Aristoteles latinus, Metaphysica, Lib. I-XIV. Recensio et translatio Guillelmi de Moerbeka, ed. G. Vuillemin-Diem, Leiden - New York - Köln: E. J. Brill, 1995, AL, t. XXV, 3.2.). En adelante: Aristoteles latinus, Metaphysica.

13 Aertsen, J. A. Medieval Philosophy as Transcendental Thought, op. cit., p. 62: "The term 'convertible' derives from the theory of the predicables that is articulated in the Topics; it means that subject and attribute are related in such a way that they are interchangeable in predication."

14 Aristoteles latinus, Metaphysica IV, 2, p. 68: "Ita uero et ens multipliciter dicitur quidem, sed omne ad unum principium. Hec enim quia substantie, entia dicuntur, illa uero quia passiones substantie (...)".

15 He aquí otra confirmación explícita de la tesis de la convertibilidad in suppositis: "Sunt enim per se convertibilia ens et quid secundum supposita, quia quidquid est ens, est quid et e converso." (Dietrich von Freiberg, DQE, 7 (3), p. 109). 
En relación con esto último, el alemán sostiene en lo relativo al ens, que éste constituye lo más común, lo más general, quedando a la cabeza del grupo de términos que se denominan communia. ${ }^{16}$ Así, nos dice en su De ente et essentia que "ente" contiene todo en sí mismo (omnia in se), en su extensión (suo ambito), según la cosa y según la significación (et re et significatione), y agrega: "el ente pues, significa la esencia de todo aquello de lo que es predicado, ya sea predicado de una substancia o de un accidente, según el Filósofo, al comienzo del libro IV de la Metafísica". ${ }^{17}$ También en su De quiditatibus entium el dominico sostiene que, según la primera división del ente (que lo divide en "ente real" y "ente de razón"), el "ente real" o "realidad de primera intención", junto con sus propiedades, se distingue en los diez géneros predicamentales. ${ }^{18}$ Encontramos pues en estos textos la confirmación del hecho de que "ente" posee un alcance universal y una circulación a través de todas las categorías: en efecto, no existe nada, fuera del Primer Principio, que no esté contenido y comprendido en el "ente" (ens) ${ }^{19}$ de manera que el ser mismo, tomado en su universalidad, no puede tener nada de "agregado" o "mezclado" con él, ya que contiene en sí mismo el universo total de las cosas. ${ }^{20}$ Es por esto que "ente" se predica de cada una de las diez categorías, la substancia y los nueve accidentes: “(...) el 'ente' dice la esencia de cada uno de los géneros predicamentales". ${ }^{21}$

Ahora bien, si "ente" se predica de todas las realidades, tanto de la substancia como de los accidentes, poseyendo entonces un alcance universal, lo mismo debe decirse de las nociones trascendentales que siguen al ente según el orden esencial establecido: en efecto, "en todo orden esencial, la razón del primero y lo que pertenece por sí al primero, deben ser conservados en lo que sigue". ${ }^{22}$ Así, por ejemplo, cuando

16 Dietrich von Freiberg, De ente et essentia, Prooemium (1), p. 25: "Quam necessarium sit non ignorare communia volentibus habere notitiam propriorum, ostendit Philosophus in suis Elenchis (...) Est autem secundum eundem Philosophum maxime commune ens et quae sunt entis per se (...)" (Dietrich von Freiberg, De ente et essentia, en Opera omnia (bajo la dirección de K. Flasch) Schriften zur Metaphysik und Theologie, Corpus Philosophorum Teutonicorum Medii Aevi, Tomus 2, introducción de K. Flasch, eds. R. Imbach, M. R. Pagnoni-Sturlese, H. Steffan, L. Sturlese, Hamburg: Felix Meiner Verlag, 1980, pp. 25-42.) En adelante: Dietrich von Freiberg, DEE.

17 Dietrich von Freiberg, DEE, I, 1 (1), p. 27: "Ens igitur, quod est generalissimum et suo ambitu omnia in se comprehendens et re et significatione, de quocumque praedicatum significat essentiam eius, de quo praedicatur, sive sit substantia sive accidens, de quo praedicatur, secundum Philosophum in principio IV Metaphysicae."

18 Dietrich von Freiberg, DQE, 4 (3), p. 104: "Dividitur autem ens prima divisione in ens secundum rem, secundum quod est res primae intentionis, cum suis proprietatibus distinctum in decem genera praedicamentorum et in ens, quod est res secundae intentionis et ens rationis, quod similiter praedictis in diversos modos distinguitur." Y también, De accidentibus, 8 (4), p. 64: "Secundum hoc igitur universitas entium, quae sunt res primae intentionis et vere res naturae, in duplicem maneriem rerum distinguitur secundum duas differentias entis in eo, quod ens, quae est prima et simplicissima omnium formalium intentionum repertarum in rebus, qua res primo distat a nihilo, distinguitur, inquam, in substantias et accidentia (...)" (Dietrich von Freiberg, De accidentibus, en Opera omnia (bajo la dirección de K. Flasch) Schriften zur Naturphilosophie und Metaphysik, Corpus Philosophorum Teutonicorum Medii Aevi, Tomus 3, introducción de K. Flasch, eds. J.-D. Cavigoli, R. Imbach, B. Mojsisch, M. R. Pagnoni-Sturlese, R. Rehn, L. Sturlese, Hamburg: Felix Meiner Verlag, 1983, pp. 53-90). En adelante: Dietrich von Freiberg, DA.

19 Dietrich von Freiberg, DEE, I, 4 (2), p. 31: “Ad quod patet responsio, quia ens et entitas significant res sub prima omnium intentione, qua res primo distat a nihilo. Sed extra primum nihil est, quod non claudatur seu comprehendatur in ipso."

20 Dietrich von Freiberg, DEE, I, 7 (8), p. 35: “(...) Ipsum autem esse secundum suam universalitatem acceptum, quia claudit in se totam rerum universitatem, nihil potest habere adiunctum seu permixtum."

21 Dietrich von Freiberg, DQE, 11 (2), p. 116: “(...) ens autem praedicat essentiam uniuscuiusque generis praedicamentorum."

22 Dietrich von Freiberg, DQE, 7 (3), p. 109: “(...) in omni autem essentiali ordine rationem primi et ea, quae sunt primi per se, oportet salvari in secundis." 
Dietrich se propone fijar la significación del término quid, segundo en la lista de las nociones trascendentales, afirma al respecto que, perteneciendo este nombre al grupo de los términos "generales", éste contiene en su significación la universalidad de los entes en cuanto a sus supuestos (secundum subiecta) o en cuanto a la cosa significada (quantum ad rem significatam). ${ }^{23}$ De manera que quid, del mismo modo que ens, significa cualquiera de las cosas reales (significat unamquamque rerum): ${ }^{24}$ "según la cosa significada, [quid] significa lo mismo que ente". ${ }^{25}$ En efecto, en el De accidentibus, el alemán sostiene explícitamente que la quididad (quiditas), que es aquello por lo que alguna cosa es manifestada en lo que es (in eo, quod quid est), se dice (aunque según una diferente ratio) tanto de la sustancia como del accidente. ${ }^{26}$ Así pues, queda claro, a la manera de ejemplo, que entre ens y quid no sólo existe una convertibilidad en cuanto a los supuestos, sino también una situación de igualdad en cuanto a su extensión universal: pues ambos se predican de todas las categorías.

No obstante, si volvemos al texto aristotélico, Metafísica IV $, 2,{ }^{27}$ el Estagirita añade una precisión de suma importancia para la comprensión de los trascendentales: sostiene, en efecto, que ens y unum significan una misma naturaleza (una natura). A este respecto, Tomás de Aquino, en su comentario a este pasaje, explica que mientras algunas cosas son algo "uno" numéricamente sin constituir sin embargo la misma naturaleza, ${ }^{28}$ (como en el caso de Sócrates, hoc album, y hoc musicum), otras en cambio, como "ente" y "uno", convirtiéndose según los supuestos, no significan diversas naturalezas, sino una sola..$^{29} \mathrm{El}$ ejemplo dado por Aristóteles lo muestra bien: ${ }^{30}$ "ente" y "uno", agregados a "hombre" o a alguna otra substancia, no constituyen ninguna "diferencia" en la realidad. Esto resulta evidente a partir de la observación de los procesos de generación y corrupción, a partir de lo cual se pone de manifiesto que cuando "hombre" es generado, "hombre que es" y "un hombre" son también generados de manera indivisible, y cuando "hombre" es corrompido, "hombre que es" y "un hombre", también lo son: así pues, "hombre", "hombre que es" y "un hombre", no sólo son numéricamente algo "uno", sino que significan la misma naturaleza en la realidad. En relación con esto, consideramos que esta otra tesis también está presente en el análisis de Dietrich acerca de los trascendentales, de forma que queda aceptada e integrada en su propia doctrina.

23 Dietrich von Freiberg, DEE, I, 2 (2), p. 28: “(...) ipsum enim quid (...) (est) de numero generalium nominum, quae sua significatione ambiunt totam universitatem entium secundum subiecta seu quantum ad rem significatam (...)."

24 Dietrich von Freiberg, DEE, I, 2 (2), p. 28: "Ens significat unamquamque rerum (...) et sicut hoc significat ens concretive, idem significat entitas in abstracto, sic, inquam, de numero talium nominum generalium est ipsum quid."

25 Dietrich von Freiberg, DEE, I, 2 (3), p. 29: “(...) secundum rem enim [quid] significat idem quod ens”.

26 Dietrich von Freiberg, DA, 15 (2-3), p. 73: “( ...) quiditas est id, quo formalissime essentiatur et constituitur res in esse secundum actum formalem quantum ad suam essentiam, ex quo etiam formali principio res talis notificatur in eo, quod quid est. (...) (3) Quamvis igitur accidentia suo modo et deminuta ratione quiditatem habeant et modo logico, ut supra habitum est, nihilominus tamen habent eam proportionaliter substantiis, videlicet quod quemadmodum in substantiis sic et in accidentibus se habet, ut, quod in constitutione accidentis cuiuscumque et in ipsius notificatione in eo, quod quid est, formalius est et per consequens magis notificativum essentiae eius, quiditas accidentis talis et sit et vocetur".

27 Aristoteles latinus, Metaphysica IV, 2, p. 68. Ver nota $\mathrm{N}^{\circ} 12$.

28 Tomás de Aquino, In Met., IV, 2, 548, p. 154: "Hoc ideo dicit, quia quaedam sunt idem numero quae non sunt una natura, sed diversae, sicut Socrates, et hoc album, et hoc musicum."

29 Tomás de Aquino, In Met., IV, 2, 548, p. 154: “(...) non diversas naturas, sed unam significant.”

30 Aristoteles latinus, Metaphysica IV, 2, p. 68. Ver nota $\mathrm{N}^{\circ} 12$. 
En efecto, como se ha hecho evidente ya en algunos de los textos citados, en numerosas ocasiones el dominico alemán afirma que ens "significa" (significat, praedicat, dicit, importat, comprehendit) la esencia (essentia) de todo aquello de lo que es predicado, ya sea predicado de una substancia o de un accidente:" "Según el Filósofo, al comienzo del libro IV de la Metafisica, el ente que es predicado de cado uno de los géneros categoriales, es predicado por esencia y dice la esencia de cado uno de ellos". ${ }^{32}$ De esta manera, una y otro (la substancia y el accidente) son llamados "entes" sólo en la medida en que poseen una esencia. ${ }^{33}$ Dietrich aclara estas tesis cuando se propone fijar la significación del esse (ens). ${ }^{34}$ En efecto, el ser significa a una cosa bajo la primera de todas las intenciones ("sub prima omnium intentione") por la cual la cosa, en cuanto tal, se encuentra a distancia de la nada ("qua res distat a nihilo inquantum huiusmodi"). Ahora bien, agrega el maestro alemán, una cosa se encuentra a distancia de la nada según toda su esencia ("secundum totam essentiam suam") y no según alguna cosa que fuera para ella un accidente ("non secundum aliquod accidens sibi"): así, el ser (esse) significa toda la esencia de la cosa, ya sea predicado de la substancia o del accidente, y lo significa absolutamente, y no en función de algún agregado accidental ("sucundum aliquod adiunctum"), como en el caso de "el hombre es blanco". ${ }^{35}$ Pues "si se dice absolutamente y sin más "el hombre

31 Por ejemplo, en su De ente et essentia: "Ens igitur (...) de quocumque praedicatum significat essentiam eius, de quo praedicatur, sive sit substantia sive accidens, de quo praedicatur, secundum Philosophum in principio IV Metaphysicae" (Dietrich von Freiberg, DEE, I, 1 (1), p. 27); "Et sic apparet de significatione huius nominis 'ens'. Importat enim in sua significatione totam essentiam eius, de quo praedicatur, sive sit substantia sive accidens (...)” (Dietrich von Freiberg, DEE, I, 1 (8), p. 28); “(...) Secundum hoc ergo ens et entitas, utrumque istorum in significando comprehendit totam essentiam rei” (Dietrich von Freiberg, DEE, I, 4 (2), p. 31); "Nunc de essentia et esse considerandum, et circa ea notandum, quod idem important in sua significatione et idem significant, quod ens et entitas, videlicet totam rei essentiam sive in substantiis sive in accidentibus (...)" (Dietrich von Freiberg, DEE, I, 5 (1), p. 31). También en su De quiditatibus entium y en su De accidentibus: “(...) ens autem praedicat essentiam uniuscuiusque generis praedicamentorum." (Dietrich von Freiberg, DQE, 11 (2), p. 116); "Et quod (...) ostendit Philosophus in principio IV Metaphysicae, ubi assumit, quod ens dictum de decem generibus praedicamentorum non praedicat nisi ipsarum rerum essentias (...). Et procedit ulterius Philosophus ostendens, quod ens secundum istam intentionem, scilicet inquantum significat uniuscuiusque rei essentiam, dicitur de aliis novem generibus in analogia ad substantiam" (Dietrich von Freiberg, DA, 10 (3), p. 66).

32 Dietrich von Freiberg, DQE, 10 (6), p. 114: "Praeterea secundum Philosophum in principio IV Metaphysicae ens praedicatum de unoquoque decem generum praedicamentorum praedicatur per essentiam et dicit essentiam uniuscuiusque eorum."

33 Dietrich von Freiberg, DEE, I, 1 (2), p. 27: "Utrumque enim illorum [substantia et accidens] dicitur ens, inquantum habet essentiam aliquam."

34 Dado que, como veremos, Dietrich no establece más que una distinción a nivel de los modi significandi entre ens y esse, no existe entre estos términos una diferencia en su significación propia y primera, esto es, en lo que se refiere a su significado lexical o significatum speciale (ver nota $\mathrm{N}^{\circ} 5$ ). De allí que lo que se diga acerca del esse, en cuanto a su significado, debe decirse también del ens. Para Tomás de Aquino, en cambio, mientras ens significa el compuesto de essentia y esse, por lo que queda definido como un habens esse, al contrario, el esse queda identificado con el actus essendi (aquel principio intrínseco por el que el ente "es").

35 Dietrich von Freiberg, DEE, I, 6 (2), p. 32: "Quia esse significat rem suam sub prima omnium intentione, qua res distat a nihilo inquantum huiusmodi - 'prima enim rerum creatarum est esse', De causis propositione 4 -, quaelibet autem res secundum totam essentiam suam distat a nihilo et non secundum aliquod accidens sibi, sed modo essentiali seu essentialiter distat, ergo esse significat totam rei essentiam, sive de substantia sive de accidente simpliciter praedicetur, et non secundum aliquod adiunctum, ut 'homo est albus' - in tali enim praedicatione non sic significat, sicut dictum est - (...)". También en su De Quiditatibus entium Dietrich utiliza fórmulas similares cuando se refiere a la ratio propia de ens: "Ens enim in eo, quod ens, prima et simplicissima omnium formalium intentionum est, qua res primo per essentiam, secundum quod essentia, distat a nihilo (...). Essentia igitur in eo, quod essentia, et non per aliquid extraneum essentiae vel accidentale distat a nihilo. Haec est igitur propria ratio essentiae et entis inquantum huiusmodi" (Dietrich von Freiberg, DQE, 1 (3), p. 99). 
es', 'es' incluye en su significación toda la esencia del hombre". ${ }^{36}$ En consecuencia, "el ser significa la esencia de la cosa de la cual es predicado absolutamente y sin más, como en el caso de 'el hombre es', 'la blancura es', y así de otros". ${ }^{37}$ En este sentido, lo mismo debe entenderse de quid (y por extensión de todos los trascendentales), a saber, que incluye en su significación toda la esencia de la cosa. ${ }^{38}$

Es esta tesis, pues, según la cual el "ente" significa la essentia de toda cosa de la que se predica (de manera que una cosa no puede ser dicha "ente" sino en función de su propia esencia y nunca en función de algún agregado accidental), la que se encuentra en el fundamento de la primera división del ente (real) en tanto que ente, a saber, la división en substancia y accidentes, tal como Dietrich la concibe. ${ }^{39}$ Según esta división, el accidente sólo es dicho "ente" "por atribución" al ente verdadero, que es la substancia: ahora bien, puesto que aquello por lo que una realidad se encuentra en primer lugar a distancia de la nada, "no puede ser algo accidental" a dicha realidad, la analogía según la cual el accidente es dicho "ente" por atribución a la substancia, debe concernir a la "esencia" misma del accidente. ${ }^{40}$ Teniendo en cuenta esto, afirma Dietrich, "toda la esencia del accidente" no consiste sino en ser una cierta "disposición y modo" de la substancia, de manera que los accidentes no poseen en verdad por sí mismos "la esencia de una quididad absoluta" ${ }^{41}$ Así pues, sólo poseen una esencia "por otro" y "según otro", y en razón de una quididad extrínseca, a saber, la de la substancia: ${ }^{42}$ y esto es así para el accidente, esencialmente, y no en función de alguna cosa accidental al accidente..$^{43}$ En efecto, lo que aquí nos interesa retener

36 Dietrich von Freiberg, DEE, I, 6 (2), p. 32: “(...) si absolute et simpliciter dicatur 'homo est', importat in sua significatione totam hominis essentiam."

37 Dietrich von Freiberg, DEE, I, 7 (11), p. 36: “(...) esse significat essentiam rei, de qua praedicatur simpliciter et absolute, ut 'homo est', 'albedo est', et sic de aliis."

38 Dietrich von Freiberg, DEE, I, 2 (3), p. 29: "Et ita ipsum quid in sua significatione importat totam essentiam rei, et hoc in concreto."

39 Sobre este punto, nos permitimos remitir a nuestro trabajo: Ocampo, Fernanda. "La división del ente en substancia y accidente según Dietrich von Freiberg, en el marco de la orientación general de su ontología", Analogía Filosófica. Revista de Filosofia, vol. 27, n² 2 (2013), pp. 23-47.

40 Dietrich von Freiberg, DA, 10 (3), p. 66: "Et quod ista analogia, qua accidens dicitur ens per attributionem ad substantiam, attendatur penes essentiam accidentis, ostendit Philosophus in principio IV Metaphysicae, ubi assumit, quod ens dictum de decem generibus praedicamentorum non praedicat nisi ipsarum rerum essentias. Cuius ratio est, quia ens nominat primam et simplicissimam omnium intentionum, qua res primo distat a nihilo: Hoc autem, quo res primo distat a nihilo, non potest esse aliquid accidentale. Et procedit ulterius Philosophus ostendens, quod ens secundum istam intentionem, scilicet inquantum significat uniuscuiusque rei essentiam, dicitur de aliis novem generibus in analogia ad substantiam. Unde Commentator dicit ibi, quod alia praedicamenta 'universaliter non dicuntur entia, nisi quia sunt dispositiones entis'.” Y también: “(...) - analogia autem huiusmodi, quae attenditur in accidentibus secundum attributionem ad substantiam, inquantum sunt entia, convenit per essentiam ipsorum, non per aliquid accidentale in eis - (...)" (Dietrich von Freiberg, DA, 16 (1), p. 75).

41 Dietrich von Freiberg, DA, 16 (2), p. 75: "Ex his igitur omnibus manifestum est, quod accidens non habet essentiam absolutae quiditatis secundum se, sed tota eius essentia est esse dispositionem et aliquem modum substantiae, et quod in hoc per se et primo differt a substantia". Y también: "Ex omnibus igitur his, quae praemissa sunt, habemus, quod accidentia non habent essentiam absolutae quiditatis secundum se ipsa, sed quod eorum essentia et entitas est esse aliquam dispositionem entis, sicut dicit Philosophus, et quod secundum hoc dicuntur entia per attributionem ad substantiam, quae vere est ens secundum suam essentiam, scilicet secundum rationem suae absolutae et propriae quiditatis - (...)" (Dietrich von Freiberg, DA, 16 (1), p. 75).

42 Dietrich von Freiberg, DA, 9 (6), p. 65: "Prima autem ratio dividendi ens secundum hoc est vel habere essentiam per se et secundum se secundum rationem suae propriae et intraneae quiditatis vel habere essentiam per aliud et secundum aliud et non secundum rationem intraneae quiditatis, sed magis, ut ita dicamus, extraneae."

43 Dietrich von Freiberg, DA, 10 (2), p. 66: "Secundum hoc etiam accidens dicitur ens per attributionem ad vere ens, quod est substantia, quia ipsum non est nisi quaedam dispositio veri entis, quod est substantia: et hoc est essentia eius. Unde non dicitur ens per attributionem ad substantiam per aliquid accidentale ipsi accidenti (...)." 
es que tanto la substancia como los accidentes son dichos "entes" en virtud de sus esencias, y no por alguna cosa "accidental" en ellos: de manera que cada género, según el modo que le es propio, es "ente" "por un modo esencial o esencialmente". 44 $\mathrm{Y}$ esto, en la interpretación del dominico alemán, es lo que muestra el Filósofo al comienzo del libro IV de la Metafísica. ${ }^{45}$

\section{La crítica de Averroes a Avicena, y su influencia en la conformación de la doctrina teodoriciana}

Ahora bien, establecida ya la estrecha vinculación existente entre el pensamiento de Dietrich acerca de los communia y la doctrina aristotélica acerca del "ente" y el "uno", nos volcaremos en lo que sigue a evidenciar cómo las tesis recién expuestas sobreentienden, como marco teórico, las interpretaciones y tomas de posición respecto de Metafisica IV, 2, por parte de los autores musulmanes: Avicena y Averroes. Si tomamos primero entonces a Avicena, es posible reconocer, en su Liber de philo-

44 Dietrich von Freiberg, DEE, I, 6 (2), p. 32: “(...) quaelibet autem res secundum totam essentiam suam distat a nihilo et non secundum aliquod accidens sibi, sed modo essentiali seu essentialiter distat, ergo esse significat totam rei essentiam, sive de substantia sive de accidente simpliciter praedicetur, et non secundum aliquod adiunctum (...)."

45 Ver los textos ya citados: Dietrich von Freiberg, DQE, 10 (6), p. 114; DA, 10 (3), p. 66; DEE, I, 1 (1), p. 27. En efecto, en Metafísica IV,1, Aristóteles sostiene que hay una ciencia que estudia el ente en cuanto ente y sus atributos esenciales, esto es, el ente y los caracteres, aspectos, propiedades que le corresponden justamente en cuanto es ente (secundum se): "Est scientia quedam que speculatur ens in quantum est ens et que huic insunt secundum se" (Aristoteles latinus, Metaphysica IV, 1, p. 67). Seguidamente, el Estagirita explica que esta ciencia no se identifica con ninguna de las ciencias particulares, ya que ninguna de ellas considera al ente en cuanto ente universalmente, sino que habiendo separado una parte de él, cada una considera tan sólo los atributos de esa parte: así, por ejemplo, las ciencias matemáticas (que estudian las cosas en tanto "cuantas"). Y termina argumentando que los principios y la causas (supremas) que esta ciencia "del ente" considera, deben ser los principios y las causas del ente "en cuanto ente" (in quantum est ens; secundum se) y no del ente en cuanto a lo que se da en él accidentalmente (secundum accidens): "Quoniam autem principia et extremas querimus causas, palam quia nature cuiusdam ipsas secundum se esse est necesse. Si ergo et entium elementa querentes hec quesierunt principia, necesse et entis elementa esse non secundum accidens sed in quantum sunt entia. Unde et nobis entis in quantum est ens prime cause sunt accipiende" (Aristoteles latinus, Metaphysica IV, 1, p. 67). En consecuencia, la primera división del ente (en substancia y accidentes), que Aristóteles introduce inmediatamente después (Metaphysica IV, 2), debe concernir al ente "en cuanto ente": esto es, al ente en lo que le pertenece por sí mismo, y no según lo que le es "accidental". De modo que tanto la substancia como los accidentes están comprendidos "esencialmente" en el ente "en cuanto ente", y de allí que sea una misma ciencia (la filosofía primera) la que estudia todas estas categorías. Ahora bien, que sea una misma ciencia la que estudia estos diversos sentidos del ente, es posible en la medida en que esta multiplicidad no está privada de una cierta unidad. Comentando este mismo capítulo, sostiene Enrico Berti que "existe algo que une, que unifica, que vincula entre sí los diversos significados del ente, a saber, el hecho de que hay uno de ellos, entre ellos, que es primero con relación a todos los otros (1003 b 5-6). ¿Qué significa ‘primero'? Condición de ser de todos los otros, condición por la cual se puede decir de los otros que son; entonces, de todos los otros se dice que son en referencia a éste, en referencia al primero. Aristóteles llama a esta situación con una expresión característica, difícil también de traducir: homônumia pros hen, homonimia relativa a uno" (Berti, Enrico. Estructura y significado de la 'Metafisica' de Aristóteles, Buenos Aires: Oinos, 2011, p. 76). Es ésta pues la lectura que hace Dietrich de las tesis aristotélicas, cuando sostiene que, de manera esencial o esencialmente, el accidente es dicho "ente", y esto necesariamente por atribución a la substancia. Así parece expresarlo Aristóteles en Metafísica IV, 2: "Ens autem multis quidem dicitur modis, sed ad unum et ad unam aliquam naturam et non equivoce (...). Ita vero et ens multipliciter dicitur quidem, sed omne ad unum principium. Hec enim quia substantie, entia dicuntur, illa vero quia passiones substantie, alia quia via ad substantiam, aut corruptiones aut privationes aut qualitates, aut effectiva aut generativa substantie, aut ad substantiam dictorum, aut horum cuiusdam negationes aut substantie" (Aristoteles latinus, Metaphysica IV, 2, p. 67-68). 
sophia prima sive scientia divina, dos grupos de tesis fundamentales en torno a las nociones de "ente" y "uno", a saber: la identidad in suppositis de estas dos nociones y así, su convertibilidad en la predicación, y la "situación de igualdad" a nivel de la extensión, esto es, la amplitud universal de estas nociones, y así su división en todas las categorías o especies. ${ }^{46}$ Tesis, todas, admitidas por numerosos autores parisinos del siglo XIII que han seguido la exposición de Aristóteles en la Metafísica, y entre ellos, como lo hemos demostrado ya, por Dietrich von Freiberg. No obstante, el aspecto menos cierto de la posición aviceniana se refiere a la cuestión de saber si "ente" y "uno", son y significan "una misma naturaleza" (una natura). En efecto, en Metafisica IV, 2, el Estagirita establece que la "substancia" de cada cosa es "una" y "ente", no por accidente, sino esencialmente: ${ }^{47}$ de modo que "hombre" es "un hombre" y "hombre que es" por sí mismo, y no en función de otra cosa, y así "uno" y "ente" son y significan la misma naturaleza, esencia o "substancia" de la cosa, a saber, en el ejemplo, "hombre". ${ }^{48}$ Sin embargo, Avicena parece no adherir a esta tesis cuando afirma que "(ambas nociones) convienen en que ninguna significa la substancia de alguna cosa" ${ }^{49}$ No resulta descabellado entonces que ens y unum hayan sido comprendidos, por algunos lectores del filósofo persa, en el sentido de "accidentes" de la esencia: ${ }^{50}$ desde este punto de vista, ambos serían disposiciones sobreañadidas a la esencia de

46 Avicenna latinus, Liber de philosophia prima, VII, 1, 9-12, p. 349: "Scias autem quod unum et ens iam parificantur in praedicatione sui de rebus, ita quod, de quocumque dixeris quod est ens uno respectu, illud potest esse unum alio respectu" (Avicenna latinus, Liber de philosophia prima sive scientia divina, ed. Simone Van Riet, 2 vol., Louvain - Leiden: E. Peeters - E.J. Brill, 1977-1980). En adelante: Avicenna latinus, Liber de philosophia prima. Y por otra parte: "Unum autem parificatur ad esse, quia unum dicitur de unoquoque praedicamentorum, sicut ens (...)" (Avicenna latinus, Liber de philosophia prima, III, 2, 17-18, p. 114).

47 Aristoteles latinus, Metaphysica IV, 2, p. 69: “(...) Amplius autem cuiusque substantia unum est non secundum accidens, similiter autem et quod quidem ens aliquid."

48 Aristoteles latinus, Metaphysica IV, 2, p. 68-69: “(...) Idem enim unus homo et homo, et ens homo et homo, et non diuersum aliquid ostendit secundum dictionem repetitam 'est homo et homo et unus homo'; palam autem quia non separatur nec in generatione nec in corruptione. Similiter autem et in uno, quare palam quia additio in hiis idem ostendit, et nichil aliud unum preter ens."

49 Avicenna latinus, Liber de philosophia prima, III, 2, 19-20, p. 114 : “(...) Conveniunt autem in hoc quod nullum eorum significat substantiam alicuius rei".

50 No obstante, el término "accidente" (accidens) parece tener distintos significados en Avicena: uno "predicamental", y otro lógico, esto es, entendido como "predicable". En este segundo sentido, el "accidente" se refiere a un predicado que, sin ser constitutivo de la esencia de una cosa (como en el caso de los géneros, las especies, y las diferencias específicas), sin embargo, acompaña a la esencia de manera inseparable, y así constituye un "concomitante" (comitans) necesario. Lo cierto es que en algunos pasajes de su Liber de philosophia prima, Avicena parece otorgar este segundo sentido de accidens al "ente" y al "uno", de modo que éstos no deberían ser interpretados sino como "concomitantes" necesarios de la cosa o esencia (en sentido lógico, y no predicamental). Así por ejemplo: “(...) nec separabitur a comitantia intelligendi ens cum illa ullo modo, quoniam intellectus de ente semper comitabitur illam, quia illa habet esse vel in singularibus vel in aestimatione vel intellectu. Si autem non esset ita, tunc non esset res" (Avicenna latinus, Liber de philosophia prima, I, 5, 79-83, p.36). Y más evidentemente: "Dico igitur quod unitas vel dicitur de accidentibus vel dicitur de substantia; cum autem dicitur de accidentibus, non est substantia, et hoc est dubium; cum vero dicitur de substantiis, non dicitur de eis sicut genus nec sicut differentia ullo modo: non enim recipitur in certificatione quidditatis alicuius substantiarum, sed est quiddam comitans substantiam, sicut iam nosti. Non ergo dicitur de eis sicut genus vel sicut differentia, sed sicut accidens" (Avicenna latinus, Liber de philosophia prima, III, 3, 80-86, p. 117). A pesar de esto, otros pasajes en la misma obra parecen, por ejemplo, reducir toda forma del "uno" o la "unidad", al principio de la cantidad y del número: "Congruit enim nobis ut in hoc loco assignemus naturam unitatis propter duas res, quarum una est quod unitas multam habet convenientiam cum esse quod est subiectum istius scientiae, alia, quod unitas initium est aliquo modo quantitatis. Quod autem initium sit numeri bene consideranti facile est intelligere (...)" (Avicenna latinus, Liber de philosophia prima, III, 1, 66-70, p. 107). Sobre esta ambigüedad, ver: De Libera, Alain. "D'Avicenne à Averroès, et retour. Sur les sources arabes de la théorie scholastique de l'un transcendantal", Arabic Sciences and Philosophy, Cambridge University Press, vol. 4 (1994), pp. 141-179. 
la cosa (res), significando así dos "naturalezas" diversas entre sí (dos disposiciones accidentales diferentes), y diversas respecto de la esencia o la "substancia" misma.

Pues bien, ésta es la lectura de Avicena que ha predominado en el mundo latino, por intermedio de Averroes. En efecto, para el cordobés, Avicena se ha equivocado en mucho: ha reducido el "uno" trascendental, convertible con el "ente" y predicado de todas las categorías ("dictum de omnibus praedicamentis"), al uno "cuantitativo", principio del número y perteneciente al género de la cantidad, ${ }^{51} \mathrm{y}$ así también, ha creído que éstos dos (el "ente" a semejanza del "uno"), constituyen disposiciones reales sobreañadidas a la substancia, ${ }^{52}$ esto es, "accidentes", en un sentido predicamental. Desde este punto de vista entonces, Avicena habría comprendido el unum (y en consecuencia, el ens), como pertenecientes al género de los nombres "denominativos" (nomina denominativa), los cuales significan un accidente y una substancia: así, por ejemplo, el término unum significa la intención (intentio) de ser indivisible ("in re carente divisibilitate"), y esta intención es diferente de aquella que significa la "naturaleza" de la cosa ("alia ab intentione quae est natura illius rei"). ${ }^{53}$ Es por esto que para Averroes, el persa habría sostenido que, siendo "ente" y "uno" nociones idénticas en cuanto al supuesto, y así convertibles, no obstante éstas no significarían una "misma intención" (eandem intentionem), así como tampoco una "misma naturaleza" (eandem naturam; eandem essentiam): 54 "ente" y "uno" serían concebidos como disposiciones accidentales (diversas de la esencia en acto). ${ }^{55}$ Estos dos términos no expresarían sino diversas disposiciones agregadas (realmente) a la esencia ("dispositiones diversas essentiae additas"). ${ }^{56}$ Pues bien: es justamente esta doctrina "aviceniana", la que el cordobés critica y rechaza, por juzgarla "no aristotélica".

51 Averroes, Aristotelis Opera cum Averrois commentariis, Metaphysicorum liber IV, comm. 3, Venetiis apud Junctas, 1562-1574, vol. 8 [réimpr. Minerva 1962], fol. 67 DE: “(...) [Avicenna] existimavit, quod unum dictum de omnibus praedicamentis, est illud unum quod est principium numerorum. Numerus autem est accidens. Unde opinatus fuit iste, quod hoc nomen unum significat accidens in entibus".

52 Averroes, Aristotelis Opera cum Averrois commentariis, Metaphysicorum liber IV, comm. 3, Venetiis apud Junctas, 1562-1574, vol. 8 [réimpr. Minerva 1962], fol. 67 B: “Avicenna autem peccavit multum in hoc, quod existimavit quod unum et ens significant dispositiones additas essentiae rei (...)."

53 Averroes, Aristotelis Opera cum Averrois commentariis, Metaphysicorum liber IV, comm. 3, Venetiis apud Junctas, 1562-1574, vol. 8 [réimpr. Minerva 1962], fol. 67 D: "Et fecerunt errare istum hominem res, quarum quaedam est, quia innuit hoc nomen unum de genere nominum denominativorum, et ista nomina significant accidens et substantias, et etiam quia existimavit quod hoc nomen unum significat intentionem in re carente divisibilitate, et quia illa intentio est alia ab intentione quae est natura illius rei."

54 Tal como señala J. Paulus, que las intenciones (intentiones) sean diversas, no sólo implica que los "conceptos" sean diversos, sino también, necesariamente, las "esencias" reales que los conceptos significan: ésta es, según Paulus, la opinión que Averroes pretende imponer a Avicena, cuando aquél comenta las afirmaciones de su predecesor, en lo que se refiere a la entidad y la unidad de las cosas (Paulus, Jean. Henri de Gand. Essai sur les tendances de sa Métaphysique, Paris: Vrin, 1938, p. 222). Así pues, según el autor, la exposición que Averroes hace de Avicena trata como equivalentes las expresiones intentio-essentia (Ibid., p. 222, Nota $\mathrm{N}^{\circ} 3$ ), de manera que la diversidad a nivel de los conceptos implica también una diversidad en la realidad. Así pues, siendo dos intentiones distintas, ens y unum son también dos essentiae distintas.

55 Averroes, Aristotelis Opera cum Averrois commentariis, Metaphysicorum liber IV, comm. 3, Venetiis apud Junctas, 1562-1574, vol. 8 [réimpr. Minerva 1962], fol. 67 CD: "Et iste homo ratiocinatur ad suam opinionem dicendo quod si unum et ens significant idem, tunc dicere ens est unum esset nugatio, quasi dicere unum est unum aut ens est ens. Et hoc non sequeretur nisi diceremus quod dicere de aliquo quod est ens et unum quod significant eandem intentionem et eodem modo. Nos autem diximus quod significant eandem essentiam sed modis diversis, non dispositiones diversas essentiae additas, et secundum hoc non est differentia apud istum hominem inter significationes quae significant eandem naturam modis diversis absque eo quod significent intentiones additas illi, et inter significationes quae significant in eadem essentiam dispositiones additas illi, scilicet, diversas ab ea in actu."

56 Idem. 
En este sentido, encontramos que cuando Dietrich establece que el esse (ens) significa la cosa según toda su esencia ("secundum totam essentiam suam"), y no según alguna cosa que sería para ella un accidente ("non secundum aliquod accidens sibi"; "non secundum aliquod adiunctum"; "non per aliquid extraneum essentiae vel accidentale"), el alemán presupone, ya sea de manera directa o indirecta, la crítica de Averroes a Avicena. Así también, lo mismo debería decirse, por extensión, del quid, y de las otras nociones que siguen en la lista de los communia y que son convertibles con el ente: las nociones trascendentales en su totalidad no expresarían disposiciones añadidas a la esencia de la cosa, sino que significarían toda la esencia de la cosa absolute et simpliciter, y no en función de algún "agregado". He aquí un pasaje en el De ente et essentia, referido a las nociones de "ente" y "uno", en el que puede observarse, aunque de manera implícita, una clara vinculación con la crítica averroísta a la posición "aviceniana":

(10) Además, según el Filósofo en el libro IV de la Metafisica, cada cosa se dice 'ente' y 'una' por su propia esencia y no por alguna disposición sobreañadida a su esencia. Pero el 'ser' y el 'ente' pertenecen a una misma razón y a un mismo orden. En cuanto a esto pues, toda cosa se dice 'ser' por su propia esencia. Y así, el 'ser' significa la esencia de cada cosa, cualquiera sea ésta. Prueba de la consecuencia: la relación de 'correr' a 'el que corre', es la misma que la de 'ser' a 'ente'. Pero es imposible que 'correr' diga una cierta disposición acerca de la substancia que corre, y que 'el que corre' no implique esta misma disposición. De modo que, por la misma razón, si 'ser' implica algo añadido a la cosa de la cual se dice, es imposible que 'ente' no implique esta misma disposición acerca de la cosa: y así, la cosa no se dirá 'ente' y 'una' por su propia esencia, lo cual es contrario al Filósofo. ${ }^{57}$

En este texto, el alemán se propone demostrar que, dado que esse y ens pertenecen a una misma razón y a un mismo orden (en la medida en que no existe entre ellos más que una distinción según los modi significandi y así no en su significación propia) ${ }^{58}$ el esse significa la misma esencia (essentia) de la cosa, y no alguna disposición añadida a la misma. En este sentido, el objetivo es dejar asentada la identidad real entre el ser (esse) y la esencia (essentia). No obstante, lo que aquí nos interesa particularmente en relación con la temática de los trascendentales, es la tesis que funge como primera premisa, a saber, que: tal como dice el Filósofo en el libro IV de la Metafisica, una cosa es "ente" y "una" por su esencia, y no en razón de alguna disposición sobreañadida a la esencia ("per suam essentiam et non per aliquam dispositionem superadditam essentiae"). Respecto a esto, se observa que, aunque la tesis es presentada bajo la autoridad de Aristóteles, según sus supuestos dichos en Metafísica IV, no obstante la cita no corresponde literalmente a ningún pasaje del texto aristoté-

57 Dietrich von Freiberg, DEE, I, 7 (10), p. 35: “(10) Praeterea secundum Philosophum in IV Metaphysicae unaquaeque res dicitur ens et unum per suam essentiam, non per aliquam dispositionem superadditam essentiae. Sed esse et ens sunt eiusdem rationis et ordinis. Quantum ad hoc ergo unaquaeque res dicitur esse per suam essentiam. Et sic esse significat essentiam uniuscuiusque rei. Probatio consequentiae: Sicut se habet currere ad currens, sic se habet esse ad ens. Sed impossibilie est, quod currere dicat aliquam dispositionem circa substantiam currentem et currens nec importet eandem dispositionem. Ergo eadem ratione, si esse importat aliquod additum rei, de qua dicitur, impossibile est, quod ens non importet eandem dispositionem circa rem. Et ita res non dicetur ens et unum per suam essentiam, quod est contra Philosophum."

$58 \quad$ Ver notas $\mathrm{N}^{\circ} 5$ y 34 . 
lico. Más bien, en la letra, parece tener una vinculación con la expresión de Averroes en su comentario a Metafísica IV, 2, en el que el cordobés critica la interpretación "aviceniana" de la doctrina aristotélica: "Avicenna autem peccavit multum in hoc, quod existimavit quod unum et ens significant dispositiones additas essentiae rei". ${ }^{59}$

A este respecto, es importante señalar que también numerosos autores nucleados en la Universidad de París, como por ejemplo, el mismo Tomás de Aquino, habían ya adherido a la lectura averroísta del texto aristotélico - crítica de la tesis "aviceniana" de la accidentalidad del "ente" y del "uno" ${ }^{60}$ Entre estos autores, señalamos principalmente al averroísta latino, Sigerio de Brabante, y a quien fuera un comprobado alumno suyo, Godofredo de Fontaines, en quienes Dietrich parece haberse inspirado en cuanto a la refutación de la tesis de la "distinción real": ${ }^{61}$ en sus argumentos, la interpretación averroísta del texto aristotélico referido al ens y al unum, adquiere un papel fundamental. Así, por ejemplo, en la quaestio 7 de sus Quaestiones in Metaphysicam, en donde Sigerio se pregunta si el ser es algo añadido a la esencia de los entes causados, el comentario de Averroes al libro IV de la Metafísica es citado en favor de una respuesta negativa, arguyendo que una cosa "es" (ente) por su esencia (per suam essentiam) y no por una disposición añadida a la esencia (per dispositio-

59 Averroes, Aristotelis Opera cum Averrois commentariis, Metaphysicorum liber IV, comm. 3, Venetiis apud Junctas, 1562-1574, vol. 8 [réimpr. Minerva 1962], fol. 67 B. La cursiva es nuestra. Con respecto a esta cuestión, comenta brevemente A. de Libera: “L'autorité d'Aristote invoquée par Dietrich est au cœur de la critique averroïste d'Avicenne. Comme dans le De accidentibus, la formulation même de la 'citation' d'Aristote est celle d'Averroès retournant la théorie avicennienne de l'étant et de l'un : une chose est dite ens et unum 'par son essence, non par une disposition surajoutée à son essence"" (De Libera, Alain. L'être et l'essence, le vocabulaire médiéval de l'ontologie. Deux traités 'De ente et essentia' de Thomas d'Aquin et Dietrich de Freiberg, Introduction et traduction C. Michon et A. de Libera, Paris: Seuil, 1996, pp. 162-203, p. 147).

60 Como hemos adelantado ya, en su comentario al libro IV de la Metafísica, el Aquinate sostiene que "ente" y "uno" son una misma cosa y una sola naturaleza ("ens et unum sunt idem et una natura": Tomás de Aquino, In Met., IV, 2, 548, p. 154). Y así explica que mientras algunas cosas son algo "uno" numéricamente sin constituir sin embargo la misma naturaleza, como en el caso de Sócrates, hoc album, y hoc musicum, otras en cambio, como "ente" y "uno", convirtiéndose según los supuestos, no significan diversas naturalezas, sino una sola ("unum autem et ens non diversas naturas, sed unam significant": Idem). Con la finalidad de probar la identidad real entre los trascendentales, Tomás presenta un argumento, sustentado en la autoridad de Averroes, según el cual si ens y unum no se predicaran per se de la esencia o "substancia" de la cosa, sino (per accidens) a causa de alguna disposición añadida, entonces esta disposición sería también "ente" y "una" a causa de otra disposición, y así al infinito (Ibid., IV, 2, 554-555, p. 155). De esta manera, concluye el Aquinate: "substantia rei est una et ens per seipsam, et non per aliquid additum" (Idem). Es en este contexto, que el dominico critica la doctrina "aviceniana" de la accidentalidad del "ente" y del "uno". No obstante, su adhesión a Averroes no es total, pues aunque Tomás rechaza dicha accidentalidad, parece mantener la distinción real entre el ser (esse) y la esencia (essentia), aunque dándole un sentido diferente al de Avicena (Ibid., IV, 2, 556-558, p. 155). Este "sentido nuevo" de la distinción, es el que Sigero de Brabante no comprenderá, cuando analice la posición de Tomás en su comentario a la Metafísica: "Etsi conclusio vera sit, modum tamen ponendi non intelligo (...)" (Sigerio de Brabante, Quaestiones in Metaphysicam, Édition revue de la reportation de Munich. Texte inédit de la reportation de Vienne, éd. W. Dunphy, Louvain-La-Neuve: Editions de l'Institut Supérieur de Philosophie, 1981 (Philosophes médiévaux, 24), q.7, 14, p. 45).

${ }_{61}$ R. Imbach ha constatado, a través del análisis de los textos de Sigerio de Brabante y de Dietrich von Freiberg, la esencial semejanza existente en lo referido a la refutación (por parte de ambos autores) de la distinción "real" entre el ser y la esencia (no admitiendo entre éstos más que una distinción según los modi significandi). Su hipótesis es que Dietrich no habría recibido directamente de Sigerio su doctrina, sino que ésta le habría sido transmitida a través de uno de los alumnos comprobados del maestro de Brabante, a saber: Godofredo de Fontaines. También en relación con Godofredo, el autor observa una todavía más evidente concordancia de doctrinas (Imbach, Ruedi. "Gravis iactura verae doctrinae...”, op. cit., pp. 201-204). Ver también: Imbach, Ruedi. "Averroistische Stellungnahmen über das Verhältnis von esse und essentia. Von Siger Von Brabant zu Thaddäus von Parma" (1981), reimpreso en Quodlibeta. Articles Choisis, Fribourg: Presses universitaires, 1996, pp. 209-251, p. 219 y ss. 
nem additam essentiae). ${ }^{62}$ También en el caso de Godofredo de Fontaines, cuando se trata de presentar argumentos en contra de la distinción real, el autor apela a la aseveración de Aristóteles en el libro IV de la Metafísica acerca del "ente" y el "uno", comentada por Averroes: $:^{63}$ tal como señala J. F. Wippel, el segundo argumento, que parte de la idea de que ens y unum son realmente idénticos, y nada añaden a la esencia de la cosa, asume que, si esto es verdadero acerca del "ente" (a saber: que "ente" no implica una real adición a la esencia de la cosa), lo mismo debe decirse respecto del ser (esse). ${ }^{64}$ En relación con esto, no resulta difícil advertir que el texto de Dietrich reproduce este mismo argumento, quedando aquí supeditada la cuestión del "ente" y el "uno" al objetivo de la refutación de la tesis de la "distinción real", en un debate ajeno a Averroes. ${ }^{65}$

Como quiera que sea, lo cierto es que aunque no exista en el discurso del alemán ninguna mención explícita de Averroes o de su comentario, resulta claro a nuestros ojos que dicho pasaje mantiene al menos una esencial dependencia doctrinal - claramente atravesada por el debate parisino en torno a la "distinción real" de finales del siglo XIII - respecto del comentario de Averroes a Metafisica IV, 2, en el que el cordobés rechaza la interpretación "aviceniana" según la cual "uno" y "ente" serían dos disposiciones añadidas a la esencia de la cosa ("dispositiones additas essentiae rei"). ${ }^{66}$ Así pues, si se tiene en cuenta entonces lo que acaba de ser afirmado, resulta incontestable para nosotros que, siguiendo los dichos aristotélicos en conformidad con la interpretación averroísta, Dietrich afirma el siguiente conjunto de tesis en lo que se refiere a las nociones trascendentales: a saber, se trata de nociones que, no sólo son idénticas según el supuesto, convertibles, y de una extensión universal en tanto se dicen de todas las categorías, sino que éstas significan, cada vez, una natura-

62 Sigerio de Brabante, Quaestiones in Metaphysicam, op. cit., q. 7, 76-79, p. 43: "Item. Averroes in eodem loco [4 Metaphysicorum]: si res est [ens] non per suam essentiam, sed per dispositionem additam essentiae, iterum illa dispositio est addita essentiae. Et si dicas quod illa dispositio est per suam essentiam, standum fuit in primo, si non procedendum est in infinitum."

63 Godofredo de Fontaines, Quodlibet III, q. 1, p. 303: "Secunda talis est. Secundum Philosophum quarto Metaphysicae, ens et unum sunt unum inter se quia nihil addunt tertio cui adiunguntur. Unde secundum ipsum, homo, ens homo et unus homo, non dicunt aliud et aliud sed id ipsum. Sed hoc non esset si ens adderet aliquam rem super essentiam eius de quo dicitur ens. Ergo et cetera" (Godofredo de Fontaines, Les quatre premiers Quodlibets de Godefroid de Fontaines, ed. M de Wulf et A. Pelzer (Les philosophes Belges, II), Louvain: Institut supérieur de Philosophie de l'Université, 1904). En la versión larga de este Quodlibet, el autor explicita su dependencia respecto del comentario de Averroes: "Cum enim unum, et bonum et ens convertantur, nec magis videtur unum importare aliquid additum ei de quo praedicatur quam ens aut e converso (...) Unde nec videtur posse melius probare intentum quam per Philosophum et Commentatorem quarto Metaphysicae, ubi ostendit Philosophus quod ens et unum inter se sunt eadem re omnino, quia addita alicui nullam diversitatem habent ad illud, ergo nec inter se (...)" (Ibid., p. 163).

${ }^{64}$ Wippel, John F. The Metaphysical Thought of Godfrey of Fontaines. A Study in Late Thirteen Century, Washington, D.C.: Catholic University of America Press, 1981, p. 55. Según el autor, este argumento habría sido anticipado ya por Sigerio de Brabante en la quaestio 7 de sus Quaestiones in Metaphysicam (Ibid., p. 56, Nota $\left.\mathrm{n}^{\circ} 45\right)$, y también formaría parte de los argumentos presentados por Enrique de Gante en su Quodlibet 1, q. 9 (fol. 6v-7r) y en su Quodlibet 10, q. 7 (fol. 416v-417r), en contra de la distinción real (Ibid., p. 59, Nota ${ }^{\circ}$ 52).

${ }_{65}$ Según R. Imbach, es Sigerio de Brabante quien parece haber aprovechado por primera vez la crítica de Averroes a Avicena en torno a la "accidentalidad" del "uno", para aplicarla a la temática del "ser" y la "esencia", de modo que existiría en Sigerio un paralelismo entre la relación de los trascendentales con la esencia, y la relación del "ser" (esse) con la essentia: todos estos términos significan la misma esencia de la cosa, y no una disposición accidental sobreviniente a la esencialidad (Imbach, Ruedi. "Averroistische Stellungnahmen über das...”, op. cit., pp. 223-224).

66 Averroes, Aristotelis Opera cum Averrois commentariis, Metaphysicorum liber IV, comm. 3, Venetiis apud Junctas, 1562-1574, vol. 8 [réimpr. Minerva 1962], fol. 67 B. 
leza o esencia bajo algún género predicamental, en la medida en que son predicadas per se de la esencia de la cosa, y no constituyen así disposiciones añadidas (como, por ejemplo, en el caso de "blanco" en relación con "hombre"). En efecto, como hemos visto, es esta predicación per essentiam, lo que caracteriza la atribución del "ente" (y de las demás nociones trascendentales) a la sustancia y los nueve accidentes, de modo que todos éstos son dichos "entes", no en razón de algo "accidental" en ellos, sino esencialmente, aunque según rationes diversas. ${ }^{67}$

No obstante, un último punto debe ser considerado atentamente: si todas estas nociones significan en cada caso la misma naturaleza o esencia colocada bajo tal o cual género categorial, y así éstas no constituyen disposiciones realmente diferentes en la cosa, ¿no sería entonces inútil una distinción entre todos estos términos? En efecto, según la interpretación de Averroes, para Avicena, si "uno" y "ente" significaran la "misma cosa" (eandem naturam; eandem essentiam; eandem intentionem), el juicio "ens est unum" constituiría una repetición inútil (nugatio): por éste motivo, el persa había creído necesario afirmar que estos dos términos no debían significar la misma naturaleza, sino disposiciones añadidas a ella. Al contrario, Averroes sostiene que no es necesario que "ente" y "uno" signifiquen disposiciones diferentes realmente agregadas a la esencia, para poder formular el juicio "ens est unum". En su opinión, no hace falta sino una distinción según el "modo": así, ens y unum difieren a nivel de los "modos" de significar, en el sentido particular de "significaciones que significan la misma naturaleza de modos diversos" ("significationes quae significant eandem naturam modis diversis") ${ }^{68}$ Ahora bien, cómo deban interpretarse estos "modos diversos" de significar, es algo que Averroes no explicita, y que los autores latinos posteriores buscarán determinar. ¿Cuál es entonces la posición de Dietrich respecto de este punto? ¿Cómo comprende el alemán la diferencia entre todos estos términos, a saber, ens, quid, unum, verum, bonum?

Pues bien, es claro que, para el dominico, los modi según los cuales los trascendentales difieren entre sí, no pueden ser meros modi significandi, esto es, modos en que las cosas son significadas a nivel del lenguaje, a saber, en la palabra o signo lingüístico. En efecto, en su De ente et essentia sostiene Dietrich que la "significación" (significatio) y el "significar" (significare), se dicen de dos maneras diversas. En primer lugar, en sentido propio (proprie), "significar" implica "designar" (designare) una cosa, por una palabra destinada a esto principalmente, por sí e inmediatamente en cuanto a la substancia de la palabra, haciendo abstracción de los diversos modos de significación: ya se trate de aquellos modos de significación esenciales (modi significandi essentiales), que son aquellos que colocan una misma palabra según su substancia en tal o cual especie de parte del discurso, (como por ejemplo, simile, que según la especie de parte del discurso es un "nombre", similare, un "verbo", y similiter, un "adverbio"); ya se trate de aquellos modos de significación accidentales (modi significandi accidentales) que, sobreentendiendo a la palabra en cuanto colocada en tal o cual especie de parte del discurso, la significan según un modo adicional (como por ejemplo, al significar una misma parte

67 Dietrich von Freiberg, DEE, I, 1 (8), p. 28: 'Et sic apparet de significatione huius nominis 'ens'. Importat enim in sua significatione totam essentiam eius, de quo praedicatur, sive sit substantia sive accidens, quamvis sub diversa ratione de ipsis praedicetur, sicut et diversa ratione convenit eis esse, et hoc essentialiter, utrique modo sibi proprio essentiali."

68 Ver nota $\mathrm{N}^{\circ}$ 55. La cursiva es nuestra. 
del discurso bajo el modo "concreto" o "abstracto", o según el caso "nominativo" o "genitivo"). ${ }^{69}$ En segundo lugar, en cambio, "significar" se dice de manera común (communiter), en tanto también es significado lo que está contenido e implicado en el concepto de la palabra y de la cosa significada de tal modo.$^{70}$ En otros términos, mientras según el primer modo de significar se hace abstracción de los modi significandi (tanto de los esenciales como de los accidentales), según el segundo modo de significar, estos modos quedan incorporados en la significación: y así, por ejemplo, mientras "blancura" y "blanco" no difieren en significación según el primer modo de significar (por lo que ambos significan la sola cualidad), sí, en cambio, según el segundo modo de significar (por lo que "blancura" significa exclusivamente la cualidad - modo abstracto -, y "blanco", el "agregado" de sustrato y cualidad - modo concreto.$-^{71}$

Ahora bien, estas distinciones son importantes para nuestro análisis, ya que en su De ente et essentia Dietrich señala que (los trascendentales) ens y quid difieren en significación, en la medida en que estos nombres generales, aunque incluyan la universalidad de los entes según los sustratos o en cuanto a la cosa significada (totam universitatem entium secundum subiecta seu quantum ad rem significatam), no obstante comportan diversas significaciones (diversas significationes important) en relación con los mismos sustratos o cosas de los que ambos se dicen. ${ }^{72}$ Así pues, mientras ens significa de manera concreta (concretive) cualquiera de las cosas reales, pero bajo la primera de todas las intenciones, según la cual una cosa "dista de la nada", en cambio, quid, que también significa las mismas cosas de manera concreta (in concreto), añade en su contenido de significación (significatum), según la propiedad de la significación (secundum proprietatis significationis), el modo esencial por el que la cosa que es significada, existe formalmente o cualitativamente, ${ }^{73}$ y que no

69 Dietrich von Freiberg, DEE, I, 3 (3), p. 29: "Sed dicendum ad istam distinguendo de significatione. Significare enim dicitur dupliciter: Uno modo significare dicitur proprie, videlicet rem aliqua voce ad hoc deputata principaliter et per se et immediate designare quantum ad substantiam vocis salvis variis modis significandi, primo videlicet quantum ad speciem partis, ut scilicet vel significet nominaliter seu verbaliter vel etiam adverbialiter, secundum quod diversi modi significandi essentiales ponunt eandem vocem secundum substantiam in alia et alia specie partis, ut simile, quod est secundum speciem partis nomen, similare verbum, similiter adverbium, sive etiam quoad alios modos significandi accidentales, puta significare per modum concreti vel abstracti in eadem parte orationis, ut albedo et album, vel secundum nominativum casum vel genitivum et sic de aliis modis significandi."

70 Dietrich von Freiberg, DEE, I, 3 (4), p. 30: "Alio modo dicitur significare communiter et magis extenso nomine significationis, ut scilicet dicatur etiam significari id, quod clauditur et importatur in intellectu vocis et rei dicto modo significatae (...)."

71 Dietrich von Freiberg, DEE, I, 3 (3), p. 30: “(...) Et sic sumendo significare proprie, sicut supra dictum est, album solam qualitatem significat secundum Philosophum, et album et albedo in significando non different (...)"; "Secundum hunc secundum modum significationis communiter acceptum patet, quod albedo et album differunt in significando. Albedo enim solam qualitatem significat, album autem significat aggregatum ex subiecto et qualitate (...)" (Dietrich von Freiberg, DEE, I, 3 (8), p. 31).

72 Dietrich von Freiberg, DEE, I, 2 (2), p. 28: "Ipsum enim quid, quamvis sit de numero generalium nominum, quae sua significatione ambiunt totam universitatem entium secundum subiecta seu quantum ad rem significatam, circa eadem tamen diversas significationes important (...)".

73 Dietrich von Freiberg, DEE, I, 2 (2-3), p. 28-29: “(...) Ens significant unamquamque rerum, sed sub prima omnium intentionum, qua res primo distat a nihilo, et sicut hoc significat ens concretive, idem significat entitas in abstracto, sic, inquam, de numero talium nominum generalium est ipsum quid. (3) Secundum rem enim significat idem quod ens, sed secundum proprietatem significationis addit in significato suo modum essentialem, quo existit, modum, inquam, essentialem in generali, quo formaliter vel qualitative existit essentialiter. Et ita ipsum quid in sua significatione importat totam essentiam rei, et hoc in concreto." 
refiere más que a la forma substancial. ${ }^{74}$ Por ejemplo, en el caso de "animal", el alma sensitiva. ${ }^{75}$ Estas tesis confirman entonces que la diferencia en la significación que Dietrich establece entre ens y quid, (y por extensión, entre todos los trascendentales), no se reduce a determinaciones que pudieran referirse a la división del discurso en sus partes (sustantivo, verbo, adverbio, etc.) y a los accidentes gramaticales que pueden sobrevenirles (caso, género, número, etc.), de los que se ocupa el gramático, ${ }^{76} \mathrm{y}$ así, ésta no debe ser ubicada a nivel del segundo modo de significar, a saber, aquel que establece una distinción tan sólo lingüística según los modi significandi (esenciales o accidentales). Pues es claro que la diferencia entre ens y quid no es como aquella existente entre "blanco" y "blancura" según el segundo modo de significar: pues ambos términos trascendentales significan las mismas cosas de manera concreta (concretive /in concreto). Por otro lado, los modi significandi parecen tener más bien su aplicación en la distinción de diversos términos reunidos en torno a un mismo trascendental (como por ejemplo, entitas, esse, essentia, en relación con ens). ${ }^{77}$

74 Dietrich von Freiberg, DEE, I, 2 (4), p. 29: "Quiditas autem, quod secundum abstractionem descendit ab eo, quod est quid, solum significat illud formale, quo res est quid essentialiter. Et hoc est, quod communiter dicitur et bene, scilicet quod in simplicibus idem est quiditas et id, quod est quid. Non sic in compositis ex materia et forma, quia ibi sola forma est quiditas (...)."

75 Dietrich von Freiberg, DEE, I, 2 (4), p. 29: “(...) secundum quod dicit Philosophus in VIII Metaphysicae, quod, si animal esset sola anima, in ipso animali quiditas et id, cuius est quiditas, essent idem. Nunc autem, quia animal compositum est ex corpore et anima, quae est forma eius et altera pars compositi, differt in eo quiditas et id, cuius est quiditas, quia sola forma est quiditas et ipsa non est totum compositum."

76 En su De quiditatibus entium, Dietrich coloca a los objetos que caen bajo la consideración de la facultad del gramático (los modos de significar y de consignificar propios de las partes del discurso, etc.), dentro del mismo género de cosas al que pertenecen los objetos de la lógica (el silogismo, la definición, el género, la especie, etc.), a saber, el género de las realidades de razón o de segunda intención: "(3) Dividitur autem ens prima divisione in ens secundum rem, secundum quod est res primae intentionis (...) et in ens, quod est res secundae intentionis et ens rationis (...). Sunt enim in huiusmodi rerum manerie, quae sunt logicae considerationis, puta syllogismus, definitio, maior et minor extremitas, locales habitudines, genus, species et huiusmodi. Sunt etiam aliqua huius generis, quae cadunt sub consideratione facultatis grammaticae, scilicet modi significandi et consignificandi partium orationis et huiusmodi" (Dietrich von Freiberg, DQE, 4 (3), p. 104).

77 Ver notas $\mathrm{N}^{\circ} 5$ y 34. Estos modos de significación (modi significandi), son utilizados por Dietrich para explicar las diferencias entre términos que poseyendo una idéntica significación (entendida en términos de significado lexical o significatum speciale) y predicándose de las mismas cosas, no obstante difieren lingüísticamente: así, por ejemplo, en el caso de ens, esse, essentia y entitas. En efecto, tal como lo manifiesta el alemán, todos estos términos implican la misma cosa (res significata) en su significación, y significan lo mismo (a saber, toda la esencia de la cosa de la que son predicados): "Nunc de essentia et esse considerandum, et circa ea notandum, quod idem important in sua significatione et idem significant, quod ens et entitas, videlicet totam rei essentiam sive in substantiis sive in accidentibus, sicut dictum est supra de entitate et ente (...)" (Dietrich von Freiberg, DEE, I, 5 (1), p. 31). Pero no sólo esto, sino que significan las mismas cosas, en todos los casos bajo la primera de todas las intenciones, según la cual una cosa en cuanto tal "dista de la nada" (significatum speciale): "Ens significat unamquamque rerum, sed sub prima omnium intentionum, qua res primo distat a nihilo, et sicut hoc significat ens concretive, idem significat entitas in abstracto (...)" (Dietrich von Freiberg, DEE, I, 2 (2), p. 28); "Ratione sic: Quia esse significat rem suam sub prima omnium intentione, qua res distat a nihilo inquantum huiusmodi (...)" (Dietrich von Freiberg, DEE, I, 6 (2), p. 32); "Ens enim in eo, quod ens, prima et simplicissima omnium formalium intentionum est, qua res primo per essentiam, secundum quod essentia, distat a nihilo. Dico autem 'essentia in eo, quod essentia', quia, sicut dicit Augustinus libro De immortalitate animae, essentia non dicitur, nisi quia est (...). Essentia igitur in eo, quod essentia (...) distat a nihilo. Haec est igitur propria ratio essentiae et entis inquantum huiusmodi" (Dietrich von Freiberg, DQE, 1 (3), p. 99). De allí que en verdad, entre todos estos términos, no haya, según Dietrich, más que una distinción según los modi significandi, esto es, a nivel del lenguaje (y no ratione, ni mucho menos, real): "Nunc de essentia et esse considerandum, et circa ea notandum, quod idem important in sua significatione et idem significant, quod ens et entitas (...) quamvis differant in modis significandi, ut videlicet esse significet per modum actus, idem autem significant ens et entitas per modum habitus et quietis. Et sic etiam differunt essentia et esse" (Dietrich von Freiberg, DEE, I, 5 (1), p. 31). Para una descripción más exhaustiva de todas estas diferencias a nivel de los modi significandi, remitimos a los primeros cinco capítulos del De ente et essentia. 
No obstante esto, el alemán advierte que la distinción entre estos nombres generales que llamamos trascendentales, tampoco se da a nivel de la res significata, como si cada uno de ellos significara una naturaleza o una esencia distinta: pues, como ya hemos visto, según la cosa significada (secundum rem), quid significa lo mismo (idem) que ens (y así también los restantes trascendentales).$^{78}$ En efecto, según lo establecido con anterioridad, los trascendentales se dicen "esencialmente" de cada una de las cosas de las que se predican (ya se trate por ejemplo de una sustancia, como "hombre", o de un accidente, como "blanco"). Pero si esto es así, si la diferencia fundamental entre dichos nombres generales no está situada a nivel de los modi significandi ni a nivel de la res significata, ¿cómo debe entenderse entonces dicha diferenciación? Dietrich nos da una respuesta cuando sostiene que dichos nombres son portadores de diversas significaciones (diversas significationes important) respecto de los mismos sustratos o cosas de los que se dicen: y así, por ejemplo, quid añade (addit) en su significado (in significato suo) un "nuevo" aspecto que no estaba explicitado en la noción de ens, y que así lo diferencia de ésta. Ahora bien, dicha "añadidura" en la significación según el significatum (en virtud de la cual un determinado término significa a una cosa de una determinada manera, esto es, acentuando un determinado aspecto), parece tener que ver con el modo en que el intelecto aprehende o concibe las cosas. Así lo prueba el siguiente texto perteneciente al De quiditatibus entium, en el que Dietrich sostiene de manera explícita que los trascendentales ens y quid, difieren según el modo de inteligir (secundum modum intelligendi):

Sin embargo, el mismo 'lo que' [quid], en tanto que 'lo que' [quid], o la quididad, en tanto que quididad, comporta por sobre la noción de ente [ens] una cierta información de la cosa, al menos respecto al modo de inteligir [saltem quoad modum intelligendi], por la cual la cosa o el ente es determinado a tal o cual esencia o naturaleza, de modo que tal cosa no solamente es ente por su distanciamiento respecto de la nada, sino que también es esto o aquello [hoc vel hoc] según una cierta información (.... ${ }^{79}$

Si nuestra interpretación es correcta entonces, los modi diversi de los que hablaba Averroes, según los cuales se dice que los trascendentales difieren, son entendidos por el dominico como verdaderos modi intelligendi, a saber, modos en los que la realidad extra-mental es "concebida", "aprehendida" o "inteligida". De manera que las diferencias entre ens, quid, unum, verum, etc., se refieren a distinciones que son dependientes del intelecto en su propia intelección de las cosas reales. Así parece sugerirlo el texto citado: una misma cosa, en la medida en que es aprehendida en cuanto "distante de la nada" es llamada ens, y en la medida en que es aprehendida como estando determinada a tal o cual esencia o naturaleza en virtud de una cierta información (i.e., la forma substancial), es llamada quid. En este sentido, aquella cosa (sea cual fuere) que "dista de la nada" y que pertenece a una "tal" naturaleza, es realmente la misma: no obstante, al aprehenderla el intelecto bajo estos dos aspectos distintos, se forman dos nociones distintas, y así también una diversidad de

78 Dietrich von Freiberg, DEE, I, 2 (3), p. 29: “(...) secundum rem enim [quid] significat idem quod ens.”

79 Dietrich von Freiberg, DQE, 1 (4), p. 99: "Ipsum autem quid in eo, quod quid, seu quiditas in eo, quod quiditas, super rationem entis importat quandam rei informationem, saltem quoad modum intelligendi, qua res seu ens determinatur ad talem vel talem essentiam vel naturam, ut res talis non solum sit ens per distantiam eius a nihilo, sed etiam sit hoc vel hoc secundum aliquam informationem (...)". 
nombres. De todas maneras, no creemos que esta tesis deba ser interpretada en el sentido de una distinción puramente "lógica" o "subjetiva", como si se tratara de un mero "producto" de la razón, carente de algún fundamento real (distinctio sine fundamento in re): ${ }^{80}$ pues "distar de la nada" (ens) ${ }^{81}$ pertenecer a tal o cual naturaleza en virtud de una cierta información (quid), ${ }^{82}$ constituir algo en lo que no cabe distinción (unum), ${ }^{83}$ desbordar fuera de sí activamente en virtud de la propia operación

80 Tal sería el caso, si se tratara de una distinctio rationis ratiocinantis, esto es, de una distinción que tiene lugar cuando nuestra mente concibe cosas distintas, sin que exista un fundamento ex parte rei para distinguirlas, (de modo que toda la distinción depende del que raciocinia): así, por ejemplo, cuando concebimos la misma cosa por conceptos sinónimos, como cuando decimos del "hombre", que es "animal racional" (Ver: Magnavacca, Silvia. Léxico técnico de filosofía medieval, Buenos Aires: Miño y Dávila, 2005, p. 233).

81 Como hemos visto, toda cosa es dicha "ente" (ens) en la medida en que "dista de la nada", y el "ser" (esse) es la primera de todas las intentiones, pues el "ser" es la primera de las "cosas creadas": "Quia esse significat rem suam sub prima omnium intentione, qua res distat a nihilo inquantum huiusmodi - "prima enim rerum creatarum est esse', De causis propositione 4 -, quaelibet autem res secundum totam essentiam suam distat a nihilo (...)" (Dietrich von Freiberg, DEE, I, 6 (2), p. 32). Es claro que para Dietrich la noción de "ente" tiene por correlato el ser real de las cosas creadas, significando a la cosa como siendo.

82 Todo ente es circunscrito a una tal o cual naturaleza en virtud de una cierta "información", y por eso es llamado quid. Dicha información es la forma substancial, y así se afirma en el Libro de las causas, que la inteligencia es hyliatim, esto es, "ente" y "forma": "Ipsum autem quid in eo, quod quid, seu quiditas in eo, quod quiditas, super rationem entis importat quandam rei informationem, saltem quoad modum intelligendi, qua res seu ens determinatur ad talem vel talem essentiam vel naturam (...) sicut de primo causato, quod est intelligentia secundum philosophos, dicitur in Libro de causis, quod ipsa est hyliatim, id est ens et forma, saltem quantum ad modum intelligendi. Et caelum et terra, homo et equus non solum sunt entia per distantiam a nihilo, sed per aliquam informationem sui determinantur ad hoc vel hoc ens secundum uniuscuiusque propriam naturam et essentiam" (Dietrich von Freiberg, DQE, 1 (4), p. 99). En su De ente et essentia, Dietrich observa de manera explícita que toda esencia o ente creado, configurado según el acto en su propia especie, procede de la forma substancial: "Praeterea in eodem libro propositione 4: 'Prima rerum creatarum est esse'. Sed esse non importat nisi actum essendi. Ergo nihil aliud est dicere 'prima rerum creatarum est esse' quam 'prima rerum creatarum est aliqua essentia secundum actum' (...). Praeterea Boethius libro De Trinitate: 'Omne esse ex forma est', id est omnis essentia secundum actum habens suam speciem est ex forma (...). 'Nihil ergo secundum materiam esse dicitur, sed secundum propriam formam'. Hucusque verba Boethii” (Dietrich von Freiberg, DEE, I, 7 (23), p. 34). Según esto, es claro que para Dietrich la noción de quid tiene por correlato la esencia o naturaleza real configurada según la forma. Sobre las nociones de quid, quiditas y definitio, nos permitimos reenviar a nuestros trabajos: Ocampo, Fernanda. "Dietrich de Freiberg: la noción de quididad en las realidades de primera y segunda intención”, en (ed.) Rubén Peretó Rivas: Temas de Metafísica Medieval, Cuadernos Medievales de Cuyo 5, Mendoza: SS\&CC Ediciones, 2011, pp. 97-111; "La concepción teodoriciana de la definitio relativa a las realidades de primera intención, y su inspiración aristotélico-averroísta”, Scripta Mediaevalia, vol. 11, n 2 (2018), pp. 103-137.

83 Dietrich afirma explícitamente la trascendentalidad del "uno": “(...) unum est de genere transcendentium et convertitur cum ente et invenitur in omnibus entibus, tam separatis quam corporalibus (...)” (Dietrich von Freiberg, De natura et proprietate continuorum, en Opera omnia (bajo la dirección de K. Flasch) Schriften zur Naturphilosophie und Metaphysik, Corpus Philosophorum Teutonicorum Medii Aevi, Tomus 3, introducción de K. Flasch, eds. J.-D. Cavigoli, R. Imbach, B. Mojsisch, M. R. Pagnoni-Sturlese, R. Rehn, L. Sturlese, Hamburg: Felix Meiner Verlag, 1983, pp. 249-274, 3 (2), p. 256). En su De natura contrariorum (16 (2), p. 95), el alemán sostiene que un ente es llamado "uno" (unum) en la medida en que no acontece en él la división (divisio), o más propiamente, la distinción (distinctio): "Hinc est etiam, quod in huiusmodi oppositione fundatur primo ratio distinctionis quorumcumque distinguibilium. Ex his autem iam trahitur ratio unius, inquantum ab aliquo removetur distinctio, quae fit per ens et non ens, et hoc est, quod dicunt, quod unum est ens indivisum sive in quo non cadit divisio. Fortassis autem magis proprie diceretur 'in quo non cadit distinctio vel remotio', si attendatur propria ratio rei (...)" (Dietrich von Freiberg, De natura contrariorum, en Opera omnia (bajo la dirección de K. Flasch) Schriften zur Metaphysik und Theologie, Corpus Philosophorum Teutonicorum Medii Aevi, Tomus 2, introducción de K. Flasch, eds. R. Imbach, M. R. Pagnoni-Sturlese, H. Steffan, L. Sturlese, Hamburg: Felix Meiner Verlag, 1980, pp. 79-135). En el mismo tratado, sostiene que la oposición sobre la que se fundan los modos reales del ente (reales modi entis) como lo uno, lo mucho y similares, es la primera y la más absoluta oposición, a saber, aquella entre afirmación y negación. Dichos términos (affirmatio et negatio) no deben ser tomados según una consideración lógica, y así, en cuanto realidades de segunda intención, sino que deben ser 
natural (bonum), ${ }^{84}$ etc., son, de todas maneras, aspectos o "atributos" reales de las cosas. En efecto, aunque no exista entre ens y quid (y así entre los trascendentales en general) una distinción "real", sin embargo cada trascendental pone de relieve algún aspecto o "atributo" particular realmente "poseído" por la cosa, aunque "distinto" tan sólo de manera "virtual" (no llegando dicha distinción a ser "actual" más que en el intelecto). ${ }^{85}$

entendidos como intenciones reales acerca del ente (intentiones reales circa res): de lo contrario, tal oposición entre afirmación y negación, no sería principio y razón de los modos reales del ente, como ser el unum, por ejemplo. Así lo expresa Dietrich: "Quantum igitur ad ipsum primum modum at,tendendum primo, quod huiusmodi oppositionum genera non sunt accipienda in proposito secundum logicam considerationem, inquantum in eis attenditur modus dicendi, quo sunt de genere secundarum intentionum. Unde affirmatio et negatio non est intelligenda enuntiatio affirmativa et negativa, quae important complexionem cum compositione affirmata vel negata, quae sunt res secundae intentionis, sed accipiendum est affirmationem et negationem quasdam simplices intentiones reales circa ens, quarum una importat positionem, alia autem eiusdem rei positivae remotionem. Alias enim huiusmodi oppositiones non essent principium et ratio realium modorum entis, qui sunt unum et multa et suarum specierum (...)" (Dietrich von Freiberg, De natura contrariorum, 13 (1), p. 93). Sobre el trascendental "uno" en Dietrich y Tomás de Aquino: Decaix, Véronique. "Les transcendantaux et l'un. Dietrich de Freiberg à l'école de Thomas d'Aquin", Bochumer Philosophisches Jahrbuch für Antike und Mittelalter, v. 16 (2013), pp. 146-162.

84 Toda cosa real o ente posee una operación propia en virtud de la cual la cosa activamente fluye hacia algo fuera de sí, y es en ese sentido que la cosa es llamada "buena". Así lo expresa en su De intellectu et intelligibili (I, 10 (2), p. 143): "Esset autem unaquaeque res superflua in natura et frustra, si destitueretur propria operatione sua, quae est finis rei, propter quem est, qua, inquam, operatione tendit in extra, quia hoc est, quo non solum invenitur entitas et veritas in unaquaque re, sed etiam bonitas, ut unaquaeque res sit ens, verum et bonum, et hoc convertibiliter, ut sit ens aliquod in se, sit verum in ordine ad intellectum, bonum autem inquantum redundans in aliud extra se active" (Dietrich de Freiberg, De intellectu et intelligibili, en Opera omnia, (bajo la dirección de K. Flasch), Schriften zur Intellekttheorie, Corpus Philosophorum Teutonicorum Medii Aevi, Tomus 1, introducción de K. Flasch, ed. B. Mojsisch, Hamburg: Meiner, 1975, pp. 137-210). Según esto, es claro que la noción de bonum posee, para el alemán, un correlato real en la cosa y su operación propia, por la cual la cosa tiende a su propio fin natural. No obstante, J. Aertsen plantea un punto que no deja de ser importante, y que parece poner en jaque la noción de bonum: "This determination of the transcendentality of the 'good', however, introduces a tension in Dietrich's metaphysics. This science considers being as being and the (transcendental) properties that belong to being as such. As we have seen, in Dietrich's view metaphysics leaves aside the extrinsic causes, both the efficient and final ones, in its study of being. But the notion of 'good' is closely connected with the idea of natural finality. Consequently, bonum must lose its metaphysical relevance, a tendency that will be manifest in Meister Eckhart's thought." (Aertsen, Jan A. Medieval Philosophy as Transcendental Thought, op. cit., p. 329). Sobre la noción de bonum en Dietrich von Freiberg y Meister Eckhart: Goris, Wouter. "Dietrich von Freiberg und Meister Eckhart über das Gute", en Dietrich von Freiberg: Neue Perspektiven seiner Philosophie, Theologie und Naturwissenschaft, Kandler, Herman, Mojsisch, Burkhard, Stamkötter, Franz-Bernhard (eds.), Amsterdam-Philadelphia: Grüner, 1999, pp. 169-188.

85 Con respecto a esto, Aertsen sostiene que Bertoldo de Moosburgo se habría inspirado en las declaraciones de Dietrich, para su tesis de que los transcendentia no poseen ninguna realidad extramental: "Das auffallendste Moment in Bertholds Darstellung ist die These, dass die 'transcendentia' keine extramentale Realität besitzen (...). Weil der Verstand Universalität in den Dingen bewirkt, besitzt 'Seiendes' kein Sein 'in rerum natura', sondern nur in der Seele. Für diese These kann Berthold kein wörtliches Zitat aus Dietrich anführen, dennoch lässt sich zeigen, dass seine Darstellung auch in diesem Punkt an Dietrichs Ausführungen orientiert ist" (Aertsen, Jan A. "Die Transzendentalienlehre bei Dietrich von Freiberg", op. cit., p. 32). El autor refiere a un pasaje del De origine rerum praedicamentatium (en Opera omnia (bajo la dirección de K. Flasch) Schriften zur Naturphilosophie und Metaphysik, Corpus Philosophorum Teutonicorum Medii Aevi, Tomus 3, introducción de K. Flasch, eds. J.-D. Cavigoli, R. Imbach, B. Mojsisch, M. R. Pagnoni-Sturlese, R. Rehn, L. Sturlese, Hamburg: Felix Meiner Verlag, 1983, pp. 135-202, 5 (33), p. 190) en el que Dietrich sostiene que, en efecto, no es éste ente o aquel otro, sino el "ente en cuanto tal" (ens simpliciter) el primer objeto del intelecto: ahora bien, puesto que la naturaleza no produce el ens simpliciter sino tan sólo en potencia (en la medida en que no hace existir en acto sino a entes individuales), es el intelecto el que constituye en acto al ens simpliciter, en la medida en que causa la universalidad en las cosas. Según esto, la "entidad" es producida por la actividad constitutiva del intelecto. Pero además, dicha actividad no sólo jugaría un rol esencial en la constitución del ens, sino también en la constitución del quid (Ibid., p. 38), del unum, y de los restantes trascendentales (Ibid., p. 46), adquiriendo 
En esto, no parece Dietrich estar alejado de la concepción de Tomás de Aquino: pues también para el Aquinate, los trascendentales, aunque idénticos re, difieren $r a$ tione. En De veritate q. 21, a. 1, sostiene, de hecho, que bonum nada añade a ens desde el punto de vista de lo real (reale), ya que si así fuera, por medio de la noción de bonum, el ente se vería contraído a un cierto género específico. De modo que, si es cierto que bonum no constituye un sinónimo de ens (ya que si lo fuera, sería una repetición inútil decir del ente, "que es bueno"), entonces es necesario que la noción de "bueno" agregue algo a la noción de "ente" (addat aliquid super ens), al menos según la razón (ad minus secundum rationem) ${ }^{86}$ En efecto, tal como afirma el Aquinate en su comentario a Metafisica IV, 2, los trascendentales, que se convierten según los supuestos y significan la misma naturaleza, ${ }^{87}$ no pertenecen sin embargo al grupo de términos que se llaman "sinónimos": pues estos términos, no sólo se convierten en el mismo supuesto y significan una misma naturaleza, sino que son unum secundum rationem (como por ejemplo, en el caso de vestis e indumentum) ${ }^{88}$ Por el contrario, ens y unum significan la misma naturaleza secundum rationes diversas ${ }^{89}$ Es ésta misma, creemos, la posición de Dietrich. En efecto, si nos volvemos al texto citado

una importancia no habitual en la tradición. No obstante esto, Aertsen también asegura que Bertoldo no ha hecho justicia al friburgués, al interpretar que los trascendentales no tienen ser en la naturaleza, sino tan sólo en el alma: "Zweitens ist (...) Berthold von Moosburgs Darstellung der Lehre von den 'transcendentia', nach welcher das transcendentale Seiende kein Sein 'in rerum natura' besitzt, sondern nur in der Seele, eine Fehldeutung. Berthold wird dem Freiberger nicht gerecht" (Ibid., p. 40). En efecto, otros pasajes del De origine afirman que una misma cosa tiene razón de "ente" en función de una diversidad de causas y según diversas rationes: 1) en cuanto es creada o causada por el primer principio o la causa primera (DORP, 5 (36), p. 191), 2) en cuanto consta de sus propios principios intrínsecos i.e., la materia y (especialmente) la forma (DORP, 1 (7), p. 139; 5 (38), p. 192) y 3) en cuanto recibe su "entidad" y "quididad" del intelecto (DORP, 5 (33), p. 49; 5 (47), p. 194; 5 (52), p. 197). Sin entrar aquí en detalle en esta difícil cuestión, lo cierto es que no parece, absolutamente hablando, que una cosa tenga la razón de "ente" (y de quid) en función de la sola constitución del intelecto: en verdad, la constitución del "ente" por el intelecto, parece quedar circunscripta a la constitución del "ente" en tanto que "objeto" universal (ens simpliciter), aunque sin perjuicio de las otras causas en los otros "niveles" de constitución. (Sobre la constitución del ente por el intelecto en Dietrich von Freiberg, ver: Porro, Pasquale. "Déduction catégoriale et prédicaments relatifs à la fin du XIIIe siècle : le De origine rerum praedicamentalium de Dietrich de Freiberg et son contexte", Quaestio, Brepols, vol. 13 (2013), pp. 197-220). Según lo dicho pues, sin bien el ens simpliciter (y así el ente en cuanto noción trascendental) se constituye en cuanto tal por la actividad del intelecto, no obstante, existe también, en la cosa real, un correlato real de esa noción. Y éste es el punto que queríamos dejar asentado.

86 Tomás de Aquino, De veritate, q. 21, a. 1: “(...) et ideo oportet quod [bonum] vel nihil addat super ens, vel addat aliquid, quod sit in ratione tantum. Si enim adderet aliquid reale, oporteret quod per rationem boni contraheretur ens ad aliquod speciale genus. Cum autem ens sit id quod primo cadit in conceptione intellectus, ut Avicenna dicit, oportet quod omne aliud nomen vel sit synonymum enti: quod de bono dici non potest, cum non nugatorie dicatur ens bonum; vel addat aliquid ad minus secundum rationem; et sic oportet quod bonum, ex quo non contrahit ens, addat aliquid super ens, quod sit rationis tantum." También en relación con la posición tomasiana, tal como se desprende de este texto, comenta G. Ventimiglia, que no se trata de una distinción sin fundamento in re: "Da questo testo, come pure da altri simili, emerge un dato difficilmente contestabile: la distinzione ratione non equivale alla nostra distinzione 'di ragione', puramente logica o rationis ratiocinantis: se infatti non vi fosse ex parte rei un qualche fondamento di quella distinzione, allora la differenza fra i trascendentali si ridurrebbe alla differenza fra termini sinonimi. Ma così, appunto, non è.” (Ventimiglia, Giovanni. 'Distinctio realis'. Ontologie aristotélico-tomistiche nella prima meta del Novecento, Lugano: EUPRESS FTL, 2012, p. 177).

87 Ver notas $\mathrm{N}^{\circ} 29$ y 60.

88 Tomás de Aquino, In Met., IV, 2, 548, p. 154: "Quaedam vero non solum convertuntur ut sint idem subiecto, sed etiam sunt unum secundum rationem, sicut vestis et indumentum."

89 Tomás de Aquino, In Met., IV, 2, 549, p. 154: "Unum autem et ens significant unam naturam secundum diversas rationes. Unde sic se habent sicut principium et causa, sed non sicut tunica et vestis, quae sunt nomina penitus synonyma.” Y también: “(...) Unde ista tria, res, ens, unum, significant omnino idem, sed secundum diversas rationes" (Ibid., IV, 2, 553, p. 155). 
al comienzo de nuestro trabajo, el alemán afirma sin ambigüedades que existe entre los trascendentales una diferencia según la ratio ("propriis rationibus differunt”), y que es en virtud de esta ratio propia a cada uno, que existe un orden esencial entre ellos. ${ }^{90}$ Es claro para nosotros que en la concepción del alemán, los "diversos modos" según los cuales las nociones trascendentales difieren y mantienen un orden entre sí, están constituidos por sus rationes diversas. Pues en todos los casos, se trata de términos que expresan un mismo ítem, una misma naturaleza o res significata, aunque en cada caso según una significación o concepción distinta del intelecto: de allí que no se trate de términos sinónimos, los cuales significan lo mismo (la misma res significata), según una idéntica ratio. Y así pues, es en virtud de esta distinción ratione entre los diversos trascendentales, que cualquier juicio que comprenda a uno y a otro como sujeto y predicado (como en el caso de "ens est unum") no resulta una repetición inútil (nugatio).

\section{Conclusión}

Hemos intentado en estas líneas reconstruir la doctrina general acerca de las nociones trascendentales del dominico alemán, Dietrich von Freiberg. En nuestra recomposición, nuestro objetivo ha sido poner de manifiesto la gran influencia que han tenido en la conformación de dicha doctrina, primero el texto de Metafísica IV, 2, y luego sus interpretaciones por parte de algunos filósofos musulmanes (especialmente Averroes) y de algunos autores latinos (de corte averroísta o influidos por la lectura de Averroes). Como fruto de nuestros análisis, podemos destacar una serie de tesis en torno a los communia que, a nuestro parecer, conforman una doctrina general bien definida, a saber: que los trascendentales son 1) algo "uno" e idéntico en cuanto al supuesto (esto es, numéricamente), 2) idénticos en cuanto a la naturaleza o esencia que significan (en la medida en que significan la misma esencia de la cosa - de la que se dicen esencialmente -, y no así diversas naturalezas sobreañadidas a ella), 3) convertibles (esto es, intercambiables en la predicación), 4) de una misma extensión (puesto que abarcan la universalidad de las cosas y circulan a través de todas las categorías, tanto de la substancia, como del accidente), y 5) diversas, según los diversos modi intelligendi o rationes que les son propias. En esta enumeración, según hemos mostrado, es la segunda tesis, la que parece haber estado más influida por la interpretación averroísta de la doctrina aristotélica en Metafísica IV, 2, y su crítica a la lectura "aviceniana". En este sentido, no podemos dejar de señalar que, aunque Dietrich ha sido un férreo opositor de la tesis de la "distinción real" entre la esencia y el acto de ser (en nuestra opinión, manifestándose esto en la ausencia de la noción de res, y la elección de quid como segundo trascendental), no obstante, en términos de su concepción general de los trascendentales, y siempre según los puntos que hemos enumerado, su doctrina no parece alejarse de la de su hermano en la Orden de Predicadores, Tomás de Aquino. 